Published in Mind, vol. 127, pp. 633-65.

\title{
Chance and the Structure of Modal Space
}

\author{
Boris Kment \\ Department of Philosophy, 1879 Hall \\ Princeton University Princeton, NJ 08544 \\ USA \\ bkment@princeton.edu
}

\begin{abstract}
The sample space of the chance distribution at a given time is a class of possible worlds. Thanks to this connection between chance and modality, one's views about modal space can have significant consequences in the theory of chance and can be evaluated in part by how plausible these implications are. I apply this methodology to evaluate certain forms of modal contingentism, the thesis that some facts about what is possible are contingent. Any modal contingentist view that meets certain conditions that I specify generates difficulties in the philosophy of chance, including a problem usually associated with Humeanism that is known as 'the problem of undermining futures'. I consider two well-known versions of modal contingentism that face this difficulty. The first version, proposed by Hugh Chandler and Nathan Salmon, rests on an argument for the claim that many individuals have their modal features contingently. The second version is motivated by the thesis that the existence of a possible world depends on the existence of the contingent individuals inhabiting it, and that many worlds are therefore contingent existents.
\end{abstract}

\section{Modality and chance}

The philosophical literature is full of debates about the general features of modal space: its plenitude, the ways worlds can differ, whether the features of the space are necessary, and so forth. To decide such disputes, it seems natural to compare the modal statements underwritten by the competing views for their plausibility, including possibility and necessity claims and counterfactuals. But often these data are inconclusive. I believe that some well-known debates about modality can be made more tractable by considering an additional source of evidence: the implications of the rival positions for the theory of physical chance.

Metaphysical modality is connected in a straightforward way to objective physical chance: there can be a non-zero chance at $t$ that $\mathrm{P}$ only if it is metaphysically possible that $\mathrm{P}$. More generally, we can think of the chance distribution at $t$ as a probability measure on the class of metaphysically possible worlds that are like actuality through $t$ and never violate the actual laws. I will call these worlds the 'possibilities that are open at $t$ ' or the

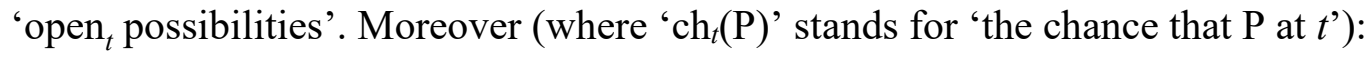


Modality-Chance Principle $(M C)$. Necessarily, $\operatorname{ch}_{t}(\mathrm{P})=x$ iff the chance measure at $t$ of the class of open ${ }_{t}$ possibilities at which P holds equals $x .{ }^{1}$

Thanks to the connection between modality and chance articulated by this principle, some theses about modal space have significant implications concerning chance and can be evaluated partly by how plausible these implications are.

In Kment (2012) I used this methodology to evaluate anti-haecceitism, arguing that the view fails to afford a sufficiently rich sample space for physical chance. In this paper, my target will be certain forms of modal contingentism, the view that some facts about what is possible are contingent. Modal contingentists hold that there are counterexamples to at least one of the characteristic axiom schemata of the modal logics S4 and S5 (' $\square$ ' and ' $\diamond$ ' express the metaphysical modalities):

$$
\begin{aligned}
& \mathbf{b} \diamond \mathrm{P} \rightarrow \diamond \mathrm{P}^{2} \\
& 5 \diamond \mathrm{P} \rightarrow \square \diamond \mathrm{P}
\end{aligned}
$$

I will argue that any form of modal contingentism that meets certain conditions yields a cluster of interrelated problematic consequences about chance, including, most importantly, the problem of undermining futures.

This problem is usually discussed as a difficulty for Humean frequentist accounts of chance (see Lewis 1994, Thau 1994, Hall 1994). Frequentists believe that the chances at $t$ are determined by the frequencies of different patterns of events throughout history. However, these frequencies are determined in part by the outcomes of post- $t$ chance processes. It may therefore be chancy at $t$ what the chances at $t$ are. For example, it could be that $\operatorname{ch}_{t}(\mathrm{P})=1 / 2$ but that there is also a positive chance at $t$ that $\operatorname{ch}_{t}(\mathrm{P}) \neq 1 / 2$. Following David Lewis, we can describe such cases by saying that the present chances 'undermine themselves'. It is implausible that undermining should be possible and it is well known that commitment to the possibility of undermining generates other serious difficulties.

The problem of undermining does not affect frequentism alone. It arises for anyone who holds that there are facts that meet two conditions: they are partly determined by the outcomes of post- $t$ chance processes and it is therefore chancy at $t$ whether they obtain, ${ }^{3}$ and they partly determine the chances at $t$. Modal contingentists have to face the problem of undermining if they believe that certain modal facts meet these two conditions, which they have to do if they think that the following is true in some scenarios.

\footnotetext{
${ }^{1}$ While MC is very widely accepted, Nolan (2016) has recently argued for a view on which the principle needs to be restricted. However, these restrictions do not affect the arguments of this paper.

${ }^{2}$ If ' $\square$ ' and ' $\diamond$ ' are duals, then this principle is equivalent to: $\square \mathrm{P} \rightarrow \square \square \mathrm{P}$.

${ }^{3}$ By saying that it is chancy at $t$ whether P holds, I mean that both $\operatorname{ch}_{t}(\mathrm{P})>0$ and $\operatorname{ch}_{t}(\ulcorner\neg \mathrm{P}\urcorner)>0$.
} 
(1) Whether P is (metaphysically) possible depends on the outcomes of post- $t$ chance processes and it is consequently chancy at $t$ whether $\mathrm{P}$ is possible.

(2) Whether $\mathrm{P}$ has a positive chance at $t$ depends on whether $\mathrm{P}$ is possible: $\operatorname{ch}_{t}(\mathrm{P})>0$

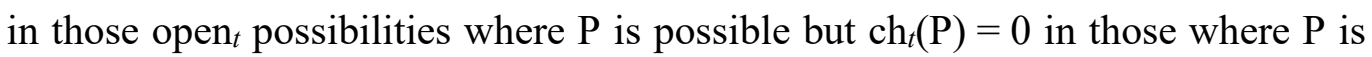
impossible.

(1) and (2) entail that there is a positive chance at $t$ that $\left(\mathrm{P}\right.$ is possible and $\left.\operatorname{ch}_{t}(\mathrm{P})>0\right)$, but there is also a positive chance at $t$ that $\left(\mathrm{P}\right.$ is impossible and $\left.\operatorname{ch}_{t}(\mathrm{P})=0\right)$. So, it is chancy at $t$ what the chances at $t$ are - the chances at $t$ undermine themselves. At least two prominent forms of modal contingentism (when combined with very plausible background assumptions) generate undermining cases in this way. The first, which I will call modalprofile contingentism (MPC), is Hugh Chandler and Nathan Salmon's well-known view that the modal profiles of many individuals are contingent. The second is what I will call modal existence contingentism (MEC), which is motivated by the thesis that many possible worlds are contingent existents.

On reflection, it is not too surprising that modal contingentism can lead to cases of undermining. The concept of chance can be used to define modal operators, such as the operators ' $\nabla_{t}^{\text {ch, }}$ and ' $\square t$ ch, considered in $\S 3.2$, where ' $\nabla_{t}^{\text {ch }} \mathrm{P}$ ' says that $\operatorname{ch}_{t}(\mathrm{P})>0$ and ' $\square t$ that $\operatorname{ch}_{t}(\mathrm{P})=1$. We can formulate principles analogous to $\mathbf{4}$ and $\mathbf{5}$ for these operators.

$$
\begin{aligned}
& \mathbf{4}_{t}^{\text {ch }} \diamond_{t}^{\text {ch }} \diamond_{t}^{\text {ch }} \mathrm{P} \rightarrow \diamond_{t}^{\text {ch }} \mathrm{P} \\
& \mathbf{5}_{t}^{\text {ch }} \diamond_{t}^{\text {ch }} \mathrm{P} \rightarrow \square_{t}^{\text {ch }} \diamond_{t}^{\text {ch }} \mathrm{P}
\end{aligned}
$$

Given the aforementioned connection between modality and chance, if there are counterexamples to $\mathbf{4}$ and $\mathbf{5}$, then they might also be counterexamples to $\mathbf{4}_{t}^{\mathrm{ch}}$ and $\mathbf{5}_{t}^{\mathrm{ch}}$. In particular, as discussed in $\S 3.2$, if there are counterexamples to $\mathbf{4}$ and $\mathbf{5}$ that meet conditions (1) and (2), then they violate $\mathbf{4}_{t}^{\text {ch }}$ and $\mathbf{5}_{t}^{\text {ch }}$. Moreover, if there are counterexample to $\mathbf{4}_{t}^{\text {ch }}$ and $\mathbf{5}_{t}^{\text {ch }}$, then they are cases of undermining.

I will discuss MPC in detail in $\S \S 2-4$ to illustrate the way in which modal contingentism can give rise to undermining cases. As we will see, proponents of MPC have to deny not only to $\mathbf{4}_{t}^{\text {ch }}$ and $\mathbf{5}_{t}^{\text {ch }}$, but also some other, equally compelling principles. These further principles are structurally similar to $\mathbf{4}_{t}^{\mathrm{ch}}$ and $\mathbf{5}_{t}^{\mathrm{ch}}$ but they are either diachronic (they concern the relationship between chance distributions at different times) or they involve modal operators that are defined in terms of the notion of an open possibility rather than in terms of chance. MPC-ists can avoid these problems only by endorsing revisionary views that seem ad hoc or by endorsing implausible views on other matters (Sects. 3.5-4). §5 will briefly consider some alternatives to MPC that avoid the problems considered in this paper. Once the problem for modal contingentism has come into clear focus through the 
discussion of MPC, it will not be difficult to see that it is arises for MEC as well. My discussion of MEC (Sect. 6) will therefore be very brief.

\section{The case for contingent modal profiles}

Suppose your living-room is graced with a table by the name of 'Woody,' made from three equally large and non-overlapping parts, A, B, and C. It seems plausible that Woody could not have been made from completely different parts. To fix ideas, assume that

(3) Necessarily, if Woody exists, he is made from at least $2 / 3$ of ABC.

However, Woody could surely have been made from slightly different parts. If a few atoms had been removed from $\mathrm{ABC}$ before a table was made from these pieces, the table would still have been Woody. Again, to fix ideas, assume that

(4) Possibly, Woody is made from parts that include no more than $2 / 3$ of ABC.

Presumably, (3) and (4) are instances of some true general principles along the following lines.

Necessity. Necessarily, where $x$ is any table and the $y$ s are $x$ 's parts, it is necessary that if $x$ exists, $x$ is made from at least $2 / 3$ of the $y$ s.

Tolerance. Necessarily, where $x$ is any table, the $y$ s are $x$ 's parts, and the $z$ s include $2 / 3$ of the $y$ s (and nothing else), $x$ could have been made from the $z \mathrm{~s}$ and some suitable other parts that are not among the $y$ s. ${ }^{4}$

By Tolerance, the following is true for some $\mathrm{X}$ and $\mathrm{Y}$ that do not overlap with $\mathrm{A}, \mathrm{B}$ or $\mathrm{C}$, or with each other.

(5) $\diamond$ Woody is made from $\mathrm{XBC}$

(6) $\square$ (Woody is made from XBC $\rightarrow \diamond$ Woody is made from XYC)

Given standard assumptions of modal logic, it follows from (5) and (6) that

(7) $\diamond \diamond$ Woody is made from XYC

However, by Necessity,

\footnotetext{
${ }^{4}$ I borrowed the name 'Tolerance' from Forbes (1985).
} 
(8) $\neg \nabla$ Woody is made from XYC

(7) and (8) together constitute a counterexample to $4(\diamond \diamond \mathrm{P} \rightarrow \diamond \mathrm{P})$.

Schema $5(\diamond \mathrm{P} \rightarrow \square \diamond \mathrm{P})$ is violated as well. Given that Woody is made from ABC, we can infer the following claims by Tolerance.

(9) $\diamond$ Woody is made from ABY

(10) $\diamond$ Woody is made from XBC

From Necessity we can infer that

(11) $\square$ (Woody is made from XBC $\rightarrow \neg \diamond$ Woody is made from ABY).

Given standard assumptions of modal logic, (10) and (11) entail that $\diamond \neg \nabla$ Woody is made from $A B Y,{ }^{5}$ and hence (if ' $\diamond$ ' and ' $\square$ ' are duals) that

(12) $\neg \square \diamond$ Woody is made from ABY

(9) and (12) together constitute a counterexample to 5.

Let us use 'modal-profile contingentism' ('MPC') for the view that (some principles like) Necessity and Tolerance are true and that $\mathbf{4}$ and $\mathbf{5}$ are invalid for the reasons described. (See Chandler 1976 and Salmon 1979, 1982, pp. 238-40, for arguments along these lines.) As we will see, MPC-ists can give different explanations for the failure of these schemata. One possibility is to account for this datum by saying that it is contingent what possible worlds there are. For example, the reason why both (7) and (8) are true is this: at some possible world $w$ there exists a possible world $w^{*}$ where Woody is made from XYC, but there does not actually exist a possible world where Woody is made from XYC. (Those who take this line need not deny that the XYC-world $w^{*}$ that exists at $w$ also exists at the actual world. Instead, they can say that at the actual world, $w^{*}$ exists but is an impossible world. In other words, they can say that it is not the existence but the modal status of XYCworlds like $w^{*}$ that is contingent.) Alternatively, an MPC-ist can adopt counterpart theory and explain failures of $\mathbf{4}$ and $\mathbf{5}$ by appealing to the non-transitivity of the counterpart relation (see Sect. 4). That approach is consistent with the thesis that the same possible worlds exist at every possible world.

Examples like the one considered provide good prima facie motivation for MPC, and it is not immediately clear what to say against the view. It is true that $\mathbf{4}$ and $\mathbf{5}$ are valid in the

\footnotetext{
${ }^{5}$ Throughout this paper I will assume that the boxes and diamonds (with or without various superscripts and subscripts), and all the other symbols to be introduced below, belong both to the object language and to the metalanguage in which I conduct the discussion.
} 
modal logic S5, which is sometimes called the 'standard modal logic' for metaphysical modality, and some authors seem to assume that it constitutes a substantial cost of a theory if it forces us to reject S5 (Linsky and Zalta 1994, 1996, Williamson 1998, 2013). But I think that that is far from obviously true. Offhand, it is hard to know what to think about 4 and $\mathbf{5}$, and it is difficult for me to imagine that anyone has strong views about these principles that are not motivated by theoretical considerations, the result of philosophical upbringing, or merely suggested by the imagery evoked by talk of possible worlds. There may be theoretical reasons for adopting S4 or S5 for metaphysical modality (Williamson 2013), but in my judgement there are at least equally weighty reasons against this choice (Adams 1981, Kment 2014, Ch. 4). However, I will argue that MPC's implications about chance make the view considerably less attractive overall. $\S 3$ will present the argument as it applies to the non-counterpart-theoretic version of MPC, while $\S 4$ will expound the slightly different argument that applies to the counterpart-theoretic variant. If we reject MPC for the reasons I will discuss, we face the question of how to accommodate the data that motivate MPC. $\$ 5$ will briefly discuss some options.

\section{Non-counterpart-theoretic MPC}

\subsection{Sufficient conditions for being Woody}

Proponents of MPC accept Tolerance and therefore believe that if Woody is actually made from $\mathrm{ABC}$, then some tables at other possible worlds that are made from BCD are identical with Woody. But they are not committed to saying that every such table is Woody. In other words: for all MPC says, being made from BCD may not be a sufficient condition for an otherworldly table to be Woody, and may not even be part of any non-trivial sufficient condition. ${ }^{6}$ It makes a difference to the arguments given below whether we assume that being made from $\mathrm{BCD}$ is part of a non-trivial sufficient condition, and (if we do) what we take that condition to be.

Where $x$ is any physical individual and $t$ is any time, let us say that a condition $\mathrm{C}$ is a pre-t condition iff satisfying $\mathrm{C}$ consists in nothing more than having certain purely qualitative features and being related in certain ways to specific individuals that exist before $t$. In other words, $\mathrm{C}$ is a pre- $t$ condition if and only if meeting $\mathrm{C}$ does not require being related in a certain way to specific individuals that come into existence at $t$ or after $t$. Let a non-initial time be a time that is not the earliest moment in history, and let us say that a condition $\mathrm{C}$ is sufficient for being $x$ just in case any entity at any possible world that satisfies $\mathrm{C}$ is identical with $x$. If the following principle is true, then, necessarily, for any

\footnotetext{
${ }^{6}$ We can obtain a sufficient condition for being Woody by conjoining being-made-from-BCD with, say, being-Woody. Sufficient conditions like that are irrelevant to my discussion. The qualification 'non-trivial' is meant to rule them out.
} 
non-initial time $t$ and any table T made from parts that existed before $t$, there is some pre- $t$ condition $\mathrm{C}$ that $\mathrm{T}$ satisfies and which is sufficient for being $\mathrm{T}$.

Sufficiency. Necessarily, if (i) the histories of the possible worlds $w$ and $w$ ' are indiscernible (in qualitative and non-qualitative respects) before some non-initial time $t$ and qualitatively indiscernible from $t$ onwards and (ii) at some time $t^{*}$ after $t$, a table is made from the same parts at $w$ and at $w^{\prime}$ and (iii) these parts existed before $t$, then the table made at the one world is identical with the table made at the other.

$\S \S 3.2-3.4$ will present the arguments on the assumption that Sufficiency is true, while $\S 3.5$ will discuss what happens if we give up Sufficiency.

Let $t$ be the time at which Woody was made. Anyone denying Sufficiency must say that there could have been two possible worlds $w_{1}$ and $w_{2}$ such that (i) the histories of $w_{1}$ and $w_{2}$ are indistinguishable in all respects before the non-initial time $t$ and qualitatively indistinguishable from $t$ onwards, (ii) at some time $t^{*}$ after $t$, a table is made from the same parts at $w_{1}$ and at $w_{2}$, (iii) these parts existed before $t$, and (iv) the table made from them is Woody at one of the worlds but not at the other. Note that this is a very strong claimmuch stronger than the thesis (which some haecceitists may accept) that there could have been two qualitatively indistinguishable possible worlds one of which features Woody while the other does not. The tables at $w_{1}$ and $w_{2}$ are not just qualitatively alike. They are made in the same way and at the same moment from numerically identical particles that are arranged in the same way. Yet, the one table is Woody while the other is not. To me it sounds implausible that there could have been such a pair of possible worlds. Sufficiency therefore seems compelling to me.

\subsection{MPC and undermining}

Let us say that the chances at $t$ undermine themselves just in case they violate the following principle.

Undermining Is Impossible (UII). For any possible world $w$ and time $t$, $\operatorname{ch}_{t, w}\left(\right.$ Chance $\left._{t, w}\right)=1$,

where Chance t,w $_{\text {is }}$ is the conjunction of those claims about the chances at $t$ that hold at $w$, and $\mathrm{ch}_{t, w}\left(\right.$ Chance $\left._{t, w}\right)$ is the chance of Chance ${ }_{t, w}$ at $t$ at $w .{ }^{7}$ UII says that it cannot be chancy at $t$ what the chances at $t$ are. That seems very compelling. Even frequentists who accept the possibility of undermining cases tend to concede their implausibility. For example,

\footnotetext{
${ }^{7}$ More precisely: Where $\mathrm{P}$ is a singular term for some claim or a variable ranging over claims, $\left\ulcorner\mathrm{ch}_{t, w}(\mathrm{P})\right\urcorner$ will abbreviate $\ulcorner\mathrm{P}$ 's chance at $t$ at $w\urcorner$. For any sentence or open formula $\mathrm{S},\left\ulcorner\mathrm{ch}_{t, w}(\mathrm{~S})\right\urcorner$ will abbreviate $\ulcorner$ the chance of the claim that $\mathrm{S}$ at $t$ at $w\urcorner$. Where $C$ is a singular term for a class of possible worlds or a variable ranging over such classes, $\left\ulcorner\mathrm{Ch}_{t, w}(C)\right\urcorner$ will abbreviate $\ulcorner C$ 's chance measure at $t$ at $w\urcorner$.
} 
David Lewis calls undermining cases 'peculiar' (1988a, postscript C). Moreover, he notes that their possibility contradicts a very intuitive principle that he takes to be central to our conception of chance: the original version of the 'Principal Principle', which relates a rational agent's credences about the chance of an event to her credence that the event will occur. $^{8}$

One way to bring out the implausibility of the idea that undermining is possible is to note its inconsistency with the following very compelling principle, which is a slightly strengthened variant of what Bigelow, Collins and Pargetter (1993) call the 'Basic Chance Principle':

Basic Chance Principle* (BCP*). For every possible world $w$, time $t$, and claim $\mathrm{P}$, if $\operatorname{ch}_{t, w}(\mathrm{P})>0$, then $\mathrm{P}$ is true at some possible world that is like $w$ up to $t$ and where the chances at $t$ are the same as at $w .^{9}$

The Modality Chance Principle (MC) entails that BCP* is true of $t$ and $w$ if UII is true of the chances at $t$ at $w .{ }^{10}$ The converse holds as well, provided that $\operatorname{ch}_{t, w}\left(\right.$ Chance $\left._{t, w}\right)$ is defined. ${ }^{11}$ Hence, on the assumption that $\mathrm{ch}_{t, w}\left(\right.$ Chance $\left._{t, w}\right)$ is defined, the instances of UII and $\mathrm{BCP} *$ that relate to $t$ and $w$ are equivalent.

\footnotetext{
${ }^{8}$ In a later paper (Lewis 1994, also see Hall 1994), Lewis offers a revised version of the Principal Principle that is consistent with the possibility of undermining but maintains that the original version is more intuitive. For more on the Principal Principle, see footnote 12.

${ }^{9}$ The original version of the principle runs as follows:
}

Suppose $x>0$ and $C h_{t w}(A)=x$. Then $A$ is true in at least one of those worlds $w$ ' that matches $w$ up to time $t$ and for which $C h_{t}(A)=x$. (Bigelow, Collins, and Pargetter 1993, p. 459)

Undermining cases generated by frequentism violate this weaker principle, those resulting from MPC only violate the strengthened version.

${ }^{10}$ To see this, suppose that (MC) holds and assume that UII is true of $t$ and $w$, i.e.

(42) $\operatorname{ch}_{t, w}\left(\right.$ Chance $\left._{t, w}\right)=1$

Let $\mathrm{H}_{t, w}$ be the conjunction of all claims about the history up to $t$ that hold at $w$. Since the past is not chancy,

(43) $\operatorname{ch}_{t, w}\left(\mathrm{H}_{t, w}\right)=1$

(42) and (43) entail that

(44) $\operatorname{ch}_{t, w}(\mathrm{P})=\operatorname{ch}_{t, w}\left(\mathrm{P} \& \mathrm{Chance}_{t, w} \& \mathrm{H}_{t, w}\right)$ for any claim $\mathrm{P}$ for which $\mathrm{ch}_{t, w}(\mathrm{P})$ is defined.

Let $\mathrm{P}$ be any claim such that $\mathrm{ch}_{t, w}(\mathrm{P})>0$. By (44), $\operatorname{ch}_{t, w}\left(\mathrm{P} \&\right.$ Chance $\left._{t, w} \& \mathrm{H}_{t, w}\right)>0$. Given MC, that entails that there is some (metaphysically) possible world where ( $\mathrm{P} \& \mathrm{Chance}_{t, w} \& \mathrm{H}_{t, w}$ ) holds, i.e. some possible Pworld that is like $w$ up to $t$ and where the chances at $t$ are the way they are at $w$. This shows that $\mathrm{BCP}^{*}$ is true of $w$ and $t$.

${ }^{11}$ The easiest way to show this is to argue for the contrapositive: if

(i) $\quad \operatorname{ch}_{t, w}\left(\right.$ Chance $\left._{t, w}\right)$ is defined and 
UII entails the following two principles considered in the introduction (where ' $\nabla_{t}^{\text {ch }} \mathrm{P}$ ' says that $\operatorname{ch}_{t}(\mathrm{P})>0$ and ' $\square t$ ch $\mathrm{P}$ ' that $\left.\operatorname{ch}_{t}(\mathrm{P})=1\right)$.

$$
\begin{aligned}
& \mathbf{4}_{t}^{\text {ch }} \diamond_{t}^{\text {ch }} \diamond_{t}^{\text {ch }} \mathrm{P} \rightarrow \diamond_{t}^{\text {ch }} \mathrm{P} \\
& \mathbf{5}_{t}^{\text {ch }} \diamond_{t}^{\text {ch }} \mathrm{P} \rightarrow \square_{t}^{\text {ch }} \diamond_{t}^{\text {ch }} \mathrm{P}
\end{aligned}
$$

By UII, any truth about the chances at $t$ has a chance of 1 at $t$. In particular, if $\operatorname{ch}_{t}(\mathrm{P})>0$, then $\operatorname{ch}_{t}\left(\operatorname{ch}_{t}(\mathrm{P})>0\right)=1$. So, $\mathbf{5}_{t}^{\text {ch }}$ holds. Similarly, UII entails that the class of worlds where the chances at $t$ are different from what they actually are has a chance measure of 0 at $t$. Hence, if the class of worlds where $\operatorname{ch}_{t}(\mathrm{P})>0$ has a positive chance measure, then actually $\operatorname{ch}_{t}(\mathrm{P})>0$. Therefore, $\mathbf{4}_{t}^{\text {ch }}$ holds as well.

MPC yields cases that violate $\mathbf{4}_{t}^{\text {ch }}$ and $\mathbf{5}_{t}^{\text {ch }}$ and therefore UII (as well as BCP*). Let us first consider an MPC-generated counterexample to $\mathbf{4}_{t}^{\text {ch }}$. I will focus for now on a version of MPC that endorses Sufficiency.

Example 1. At $t$, you resolve to toss a fair coin to decide whether to make a table from $\mathrm{ABC}, \mathrm{BCD}$, or CDE. If the coin lands heads, you will make the table from ABC. If it comes up tails, you will toss it again. If the second toss lands heads, you will make a table from BCD, if it comes up tails, you will instead make a table from CDE. In fact, the first toss comes up heads and you make a table from ABC. You call the table 'Woody'.

By Sufficiency, there must be some pre-t condition X (in the sense defined in Sect. 3.1) that Woody satisfies and which is a sufficient condition for amy table at any possible world to be Woody. Let us assume that you have seen to it ahead of time that, if the first toss comes up heads and you make a table from $\mathrm{ABC}$, then that table will meet condition $\mathrm{X}$.

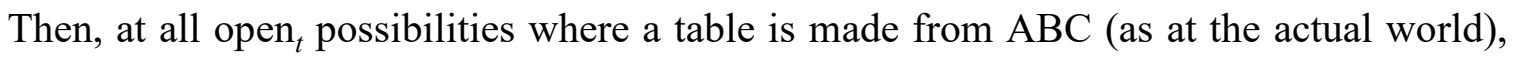
that table is Woody. In a similar way, you have set things up so that at any open ${ }_{t}$ possibility where a table is made from BCD, that table is Woody. Finally, let us suppose you have

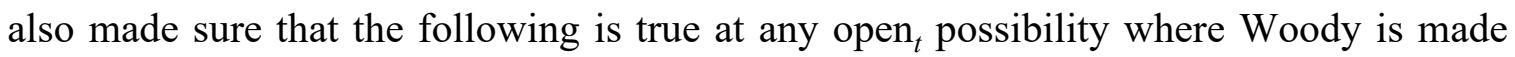
from BCD: at any open ${ }_{t}$ possibility where a table is made from CDE, that table is Woody. (Of course, by Necessity, it is not true at the actual world that a table that is made from $\mathrm{CDE}$ at another open $t$ possibility is Woody.)

\section{(ii) UII fails for $t$ and $w$,}

then BCP* fails for $t$ and $w$. Suppose that (i) and (ii) hold. By (ii), not $\operatorname{ch}_{t, w}\left(\mathrm{Chance}_{t, w}\right)=1$. Given (i), it follows that $\mathrm{ch}_{t, w}\left(\right.$ Chance $\left._{t, w}\right)<1$. So, $\operatorname{ch}_{t, w}\left(\neg \mathrm{Chance}_{t, w}\right)>0$. And yet, by the definition of ' $\mathrm{Chance}_{t, w}$ ', there is no possible $\neg$ Chance $_{t, w}$-world that is like $w$ up to $t$ and where the chances at $t$ are the same as at $w$. That violates $\mathrm{BCP} *$. 
I will use ' $\mathrm{ABC} \mathrm{W}_{\mathrm{W}}$ ' both as a name for, and as an abbreviated statement of, the claim that Woody is made from $\mathrm{ABC}$ (a harmless ambiguity). ' $\mathrm{BCD}_{\mathrm{W}}$ ' and ' $\mathrm{CDE} \mathrm{W}_{\mathrm{W}}$ ' will be understood analogously. Moreover, 'ABC' will both name and abbreviate the claim that some table is made from $\mathrm{ABC}$ (and analogously for ' $\mathrm{BCD}$ ' and ' $\mathrm{CDE}$ '). Figure 1 depicts the situation at the actual world. The black path represents the course that events are in fact taking. Unrealized open ${ }_{t}$ possibilities are greyed out.

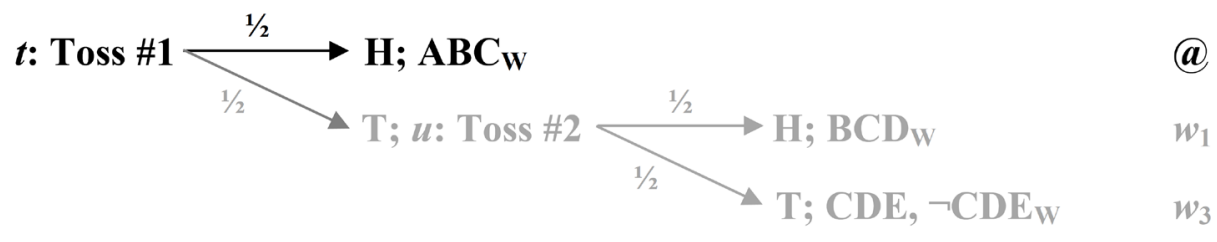

Figure 1. The open ${ }_{t}$ possibilities at the actual world and their chances in Example 1.

Since MPC-ists hold that the table is not Woody at open ${ }_{t}$ possibilities where it is made from CDE, they have to accept the following:

(13) $\operatorname{ch}_{t}\left(\mathrm{CDE}_{\mathrm{W}}\right)=0$

Moreover, the following also holds at the actual world:

(14) $\operatorname{ch}_{t}\left(\left\{w_{1}\right\}\right)>0$

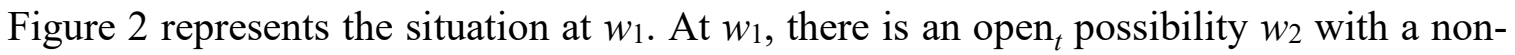
zero chance of actualization at $t$ where Woody is made from CDE. By the Modality Chance Principle (MC) stated in the introduction, that entails the following:

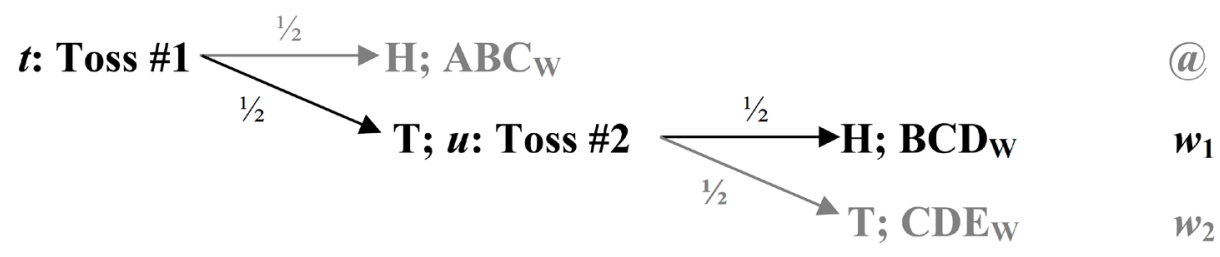

Figure 2. The open ${ }_{t}$ possibilities at $w_{1}$ and their chances in Example 1

(15) At $w_{1}, \operatorname{ch}_{t}\left(\mathrm{CDE}_{\mathrm{W}}\right)>0$

Given (14), (15) and MC, the following must hold at the actual world:

(16) $\operatorname{ch}_{t}\left(\operatorname{ch}_{t}\left(\mathrm{CDE}_{\mathrm{W}}\right)>0\right)>0$ 
(13) and (16) together form a counterexample to $\mathbf{4}_{t}^{\text {ch }}$ : (16) says that $\diamond_{t}^{\text {ch }} \diamond_{t}^{\text {ch }} \mathrm{CDE}$, while (13) tells us that $\neg \vartheta_{t}^{\text {ch }} \mathrm{CDE}_{\mathrm{W}}$. By the same token, (13) and (16) also constitute a case of undermining: $\operatorname{ch}_{t}\left(\mathrm{CDE}_{\mathrm{W}}\right)=0$, yet there is a non-zero chance at $t$ that $\operatorname{ch}_{t}\left(\mathrm{CDE}_{\mathrm{W}}\right) \neq 0$. This example of undermining follows the pattern described in the introduction: $\mathrm{CDE}_{\mathrm{W}}$ 's chance at $t$ depends on whether $\mathrm{CDE}_{\mathrm{W}}$ is possible- $\mathrm{ch}_{t}\left(\mathrm{CDE}_{\mathrm{W}}\right)>0$ at those open $\operatorname{possibilities}$ where $\diamond \mathrm{CDE}_{\mathrm{W}}$, but $\mathrm{ch}_{t}\left(\mathrm{CDE}_{\mathrm{W}}\right)=0$ at those where $\neg \diamond \mathrm{CDE}_{\mathrm{W}}$. Moreover, at $t$ it is still chancy whether $\mathrm{CDE}_{\mathrm{W}}$ is possible, since CDEw's modal status depends on the outcome of the first toss, which will not be determined until the coin hits the ground. It is therefore chancy at $t$ whether $\mathrm{CDE}_{\mathrm{W}}$ has a positive chance at $t$.

A variant of Example 1 shows that MPC conflicts with $\mathbf{5}_{t}^{\text {ch }}$ as well. Suppose that actually, the first toss comes up tails and the second heads and Woody is made from BCD. Then:

(17) $\operatorname{ch}_{t}(\mathrm{ABCW})>0$.

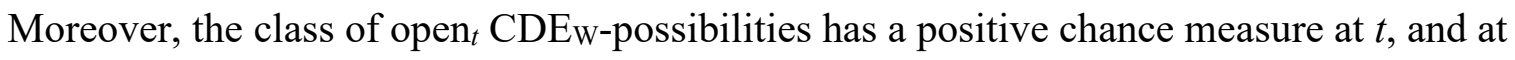

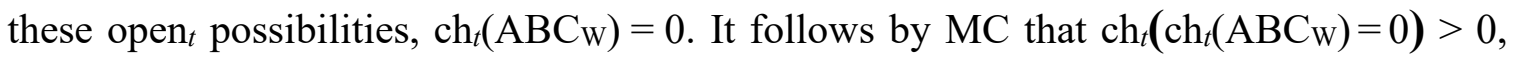
and therefore:

(18) $\operatorname{ch}_{t}\left(\operatorname{ch}_{t}\left(\mathrm{ABC}_{\mathrm{W}}\right)>0\right) \neq 1$.

(17) and (18) constitute a counterexample to $\mathbf{5}_{t}^{\text {ch }} \cdot{ }^{12}$

\footnotetext{
12 The original version of the Principal Principle $\left(\mathrm{PP}_{\mathrm{O}}\right)$ proposed in Lewis 1986a tells us that one's credence $\operatorname{Cr}\left(\mathrm{P} \mid \operatorname{ch}_{t}(\mathrm{P})=x\right)$ ought to equal $x$, provided you have no 'inadmissible' evidence relative to $\mathrm{P}$ and $t$, i.e. your evidence bears on P only by bearing on what P's chance is at $t$. Here is an example that shows that MPC-ists who accept Sufficiency have to reject $\mathrm{PP}_{\mathrm{O}}$. You explain to me that you will use a random device with three equiprobable possible outcomes to determine whether to make a table from $\mathrm{ABC}, \mathrm{BCD}$, or CDE. Leaving your workshop at $t$, I am certain that
}

(48) $\operatorname{ch}_{t}(\mathrm{ABC})=\operatorname{ch}_{t}(\mathrm{BCD})=\operatorname{ch}_{t}(\mathrm{CDE})=1 / 3$

Returning later, I am introduced to the finished table (Woody) but not told from which parts it was made. It seems permissible to divide my credence over the three possibilities:

(49) $\operatorname{Cr}\left(\mathrm{ABC}_{\mathrm{W}}\right)=\mathrm{Cr}\left(\mathrm{BCD}_{\mathrm{W}}\right)=\mathrm{Cr}\left(\mathrm{CDE}_{\mathrm{W}}\right)=1 / 3$

I am certain that MC and (50) are true (MPC-ists who accept Sufficiency cannot deny that it can be rational to accept (50)).

also (as an MPC-ist) of the following:

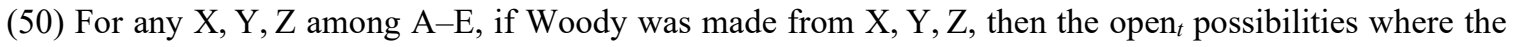
table you make is Woody are just those where the table is made from parts that include at least two of $\mathrm{X}, \mathrm{Y}, \mathrm{Z}$. 


\subsection{Expected future chances}

$\mathbf{4}_{t}^{\text {ch }}, \boldsymbol{5}_{t}^{\text {ch }}$, and UII are synchronic principles: they are about the chances at a single time $t$. But MPC also conflicts with a very compelling diachronic principle about chance, that is, a principle that deals with the relationship between chances at different times. Let us start with an illustration of this principle. Sitting in front of two buttons, you are about to throw a fair six-sided die. If it lands 6, you will push the left button, an action that has an $80 \%$ chance of causing an explosion. If any other number comes up, you will push the right button, giving the explosion a $20 \%$ chance of occurring. What is the current chance of an explosion? Obviously, it is $1 / 6 \times 80 \%+5 / 6 \times 20 \%=30 \%$. The current chance equals the average of the different possible future chances, weighted by the present chances of these future chances. More generally and formally: Let $t$ and $u$ be times and let us write ' $t<u$ ' for ' $t$ is earlier than $u$ '. Let $\mathrm{Ch}_{u, w}(\mathrm{P})$ be the function that assigns to every open ${ }_{t}$ possibility $w$ the chance that $\mathrm{P}$ has at time $u$ at $w$ if this chance is defined (and which is undefined for $w$ otherwise). If the expected value of $\mathrm{Ch}_{u, w}(\mathrm{P})$ relative to the probability function $\mathrm{ch}_{t}$ is defined, then let us call it ' $\mathrm{E}_{\mathrm{ch}_{t}}\left(\mathrm{Ch}_{u, w}(\mathrm{P})\right)$ '. Our example illustrates the following principle:

$$
\begin{aligned}
& \text { Expected Chance Principle (ECP). } \quad \operatorname{ch}_{t}(\mathrm{P})=\mathrm{E}_{\mathrm{ch}_{t}}\left(\mathrm{Ch}_{u, w}(\mathrm{P})\right) \text { whenever } t<u \text {, } \\
& \text { provided } \mathrm{E}_{\mathrm{ch}_{t}}\left(\mathrm{Ch}_{u, w}(\mathrm{P})\right) \text { is defined. }
\end{aligned}
$$

As the bomb example illustrates, ECP is useful for calculating or estimating the present chance that a certain event will occur in the future, in particular when its occurrence is

(50) entails that if $\mathrm{CDE}_{\mathrm{W}}$, then there are no open $t_{t}$ possibilities where $\mathrm{ABC}$, so that (by $\left.\mathrm{MC}\right) \operatorname{ch}_{t}\left(\mathrm{ABC} \mathrm{C}_{\mathrm{W}}\right)=0$. Hence, $\operatorname{Cr}\left(\mathrm{ch}_{t}\left(\mathrm{ABC}_{\mathrm{W}}\right)=0 \mid \mathrm{CDE}_{\mathrm{W}}\right)=1$ and therefore

(51) $\operatorname{Cr}\left(\operatorname{ch}_{t}\left(\mathrm{ABC}_{\mathrm{W}}\right)=1 / 3 \mid \mathrm{CDE}_{\mathrm{W}}\right)=0$

Moreover, (50) entails that if either $\mathrm{ABC}_{\mathrm{W}}$ or $\mathrm{BCD}_{\mathrm{W}}$ is true, then the open $\mathrm{ABC}_{\mathrm{W}}$-possibilities are just those where $\mathrm{ABC}$ holds, so that (by $(48)$ and $\mathrm{MC}) \mathrm{ch}_{t}\left(\mathrm{ABC}_{\mathrm{W}}\right)=1 / 3$. So,

(52) $\operatorname{Cr}\left(\operatorname{ch}_{t}\left(\mathrm{ABC}_{\mathrm{W}}\right)=1 / 3 \mid \mathrm{BCD}_{\mathrm{W}}\right)=1$

$$
\operatorname{Cr}\left(\operatorname{ch}_{t}\left(\mathrm{ABC}_{\mathrm{W}}\right)=1 / 3 \mid \mathrm{ABC}_{\mathrm{W}}\right)=1
$$

(49), (51), and (52) entail that $\operatorname{Cr}\left(\mathrm{ABC}_{\mathrm{W}} \mid \mathrm{ch}_{t}\left(\mathrm{ABC}_{\mathrm{W}}\right)=1 / 3\right)=1 / 2$. But since I have no inadmissible evidence relative to $\mathrm{ABC}_{\mathrm{W}}$ and $t, \mathrm{PP}_{\mathrm{O}}$ entails that $\mathrm{Cr}\left(\mathrm{ABC}_{\mathrm{W}} \mid \operatorname{ch}_{t}\left(\mathrm{ABC}_{\mathrm{W}}\right)=1 / 3\right)$ ought to equal $1 / 3$.

It would require more work to show that cases like this create a serious problem for MPC-ists endorsing Sufficiency. MPC-generated counterexamples to $\mathrm{PP}_{\mathrm{O}}$ concern de re credences about specific individuals, and there may be independent reasons for thinking that $\mathrm{PP}_{\mathrm{O}}$ yields false predictions when applied to some singular beliefs (cf. Hawthorne and Lasonen-Aarnio 2009, p. 97). If so, then $\mathrm{PP}_{\mathrm{O}}$ needs to be revised in response to these counterexamples in any case, and for all that has been shown, the revised principle might be consistent with the combination of MPC and Sufficiency. It is also worth mentioning that the (admittedly less compelling) undermining-resistant 'New Principal Principle' proposed in Lewis 1994 and Hall 1994 can be accepted by MPC-ists who endorse Sufficiency. 
known to depend on the outcomes of a small number of successive future random processes.

The diachronic principle ECP does not follow from the synchronic principle UII alone. However, given the following plausible diachronic principle, it can be shown that if UII is true of $t$-if the chances at $t$ do not undermine themselves - then ECP is true of $t$ as well: ${ }^{13}$

13 Proof. (1) Preliminaries. (a) Terminology. Let $\mathrm{ch}_{t, w}$ and $\mathrm{ch}_{u, w}$ be the chance functions at $w$ at $t$ and at $u$, respectively, let $\mathrm{ch}_{t}$ be the chance function that in fact prevails at $t$, and let Chance $t$ be the conjunction of all claims about the chances at $t$ that are in fact true. (b) Law of total probability (LTP). Consider some claim A and some partition $\mathrm{X}$ of the sample space $\Omega$ of probability function $p$. For every $w \in \Omega$, let $\mathrm{X}^{w}$ be the cell of $\mathrm{X}$ containing $w$, and let $\mathrm{P}\left(\mathrm{A} \mid \mathrm{X}^{w}\right)$ be the function that, for every $w \in \Omega$, assigns to $w$ the number $p\left(\mathrm{~A} \mid \mathrm{X}^{w}\right)$ if $p\left(\mathrm{~A} \mid \mathrm{X}^{w}\right)$ is defined (and which is undefined for $w$ otherwise). If the expected value of $\mathrm{P}\left(\mathrm{A} \mid \mathrm{X}^{w}\right)$ relative to $p$ is defined, then let us call it ' $\mathrm{E}_{p}\left(\mathrm{P}\left(\mathrm{A} \mid \mathrm{X}^{w}\right)\right)$ '. LTP tells us that $p(\mathrm{~A})=\mathrm{E}_{p}\left(\mathrm{P}\left(\mathrm{A} \mid \mathrm{X}^{w}\right)\right)$, provided $\mathrm{E}_{p}\left(\mathrm{P}\left(\mathrm{A} \mid \mathrm{X}^{w}\right)\right)$ is defined. (When $\mathrm{X}$ has only countably many members, $\mathrm{X}_{1}, \mathrm{X}_{2}, \ldots$, we obtain a familiar special case of LTP: $p(\mathrm{~A})=\Sigma_{i}\left[p\left(\mathrm{~A} \mid \mathrm{X}_{i}\right) \times p\left(\mathrm{X}_{i}\right)\right]$ if the terms are defined.) When $\mathrm{P}\left(\mathrm{A} \mid \mathrm{X}^{w}\right)$ is undefined for some $w \in \Omega$, then $\mathrm{E}_{p}\left(\mathrm{P}\left(\mathrm{A} \mid \mathrm{X}^{w}\right)\right)$ is undefined and LTP as stated does not apply. But we can generalize LTP to cover those cases where $p\left(\left\{w \in \Omega: \mathrm{P}\left(\mathrm{A} \mid \mathrm{X}^{w}\right)\right.\right.$ is undefined $\left.\}\right)=0$. Call a function $f: \Omega \rightarrow[0,1]$ an extension of $\mathrm{P}\left(\mathrm{A} \mid \mathrm{X}^{w}\right)$ if and only if $p\left(\left\{w \in \Omega: f(w)=\mathrm{P}\left(\mathrm{A} \mid \mathrm{X}^{w}\right)(w)\right\}\right)=1$ and $\mathrm{E}_{p}(f)$ is defined. Any two extensions $f$ and $f^{*}$ of $\mathrm{P}\left(\mathrm{A} \mid \mathrm{X}^{w}\right)$ are almost surely equal (i.e., $\left.p\left(\left\{w \in \Omega: f(w)=f^{*}(w)\right\}\right)=1\right)$ and therefore have the same expectation relative to $p$. If $\mathrm{P}\left(\mathrm{A} \mid \mathrm{X}^{w}\right)$ has an extension $f$ and $\mathrm{E}_{p}(f)=x$, then let us call $x$ the quasi-expectation of $\mathrm{P}\left(\mathrm{A} \mid \mathrm{X}^{w}\right)$ relative to $p$ or ' $\mathrm{E}_{p}^{*}\left(\mathrm{P}\left(\mathrm{A} \mid \mathrm{X}^{w}\right)\right)$ '. LTP generalizes to what I will call ' $\mathrm{LTP}^{*}$ ': $p(\mathrm{~A})=\mathrm{E}_{p}^{*}\left(\mathrm{P}\left(\mathrm{A} \mid \mathrm{X}^{w}\right)\right)$ if $\mathrm{E}_{p}^{*}\left(\mathrm{P}\left(\mathrm{A} \mid \mathrm{X}^{w}\right)\right)$ is defined.

(2) Proof of demonstrandum. Suppose that UII and (19) are true. Moreover, assume the following:

(53) $t<u$

(54) $\mathrm{E}_{\mathrm{ch}_{t}}\left(\mathrm{Ch}_{u, w}(\mathrm{P})\right)$ is defined.

Consider the partition of the sample space $\mathrm{OP}_{t}$ of $\mathrm{ch}_{t}$ into equivalence classes of worlds that have the same post- $t$ history up to $u$, i.e. whose histories are indistinguishable during the half-open temporal interval $(t, u]$. For any $w \in \mathrm{Op}_{t}$, let $\mathrm{H}_{(t, u], w}$ be the cell of the partition containing $w$. Let $\mathrm{Ch}_{t}\left(\mathrm{P} \mid \mathrm{H}_{(t, u], w}\right)$ be the function that, for every $w \in \mathrm{Op}_{t}$, assigns $\operatorname{ch}_{t}\left(\mathrm{P} \mid \mathrm{H}_{(t, u], w}\right)$ to $w$ if $\operatorname{ch}_{t}\left(\mathrm{P} \mid \mathrm{H}_{(t, u], w}\right)$ is defined and that is undefined for $w$ otherwise. We can infer (55) from LTP*, (56) from UII, and (57) from (19) and (53).

(55) $\operatorname{ch}_{t}(\mathrm{P})=\mathrm{E}_{\mathrm{ch}_{t}} *\left(\mathrm{Ch}_{t}\left(\mathrm{P} \mid \mathrm{H}_{(t, u], w}\right)\right)$ if $\mathrm{E}_{\mathrm{ch}_{t}}{ }^{*}\left(\mathrm{Ch}_{t}\left(\mathrm{P} \mid \mathrm{H}_{(t, u], w}\right)\right)$ is defined.

(56) $\operatorname{ch}_{t}\left(\right.$ Chance $\left._{t}\right)=1$

(57) $\operatorname{ch}_{u, w}(\mathrm{P})=\operatorname{ch}_{t, w}\left(\mathrm{P} \mid \mathrm{H}_{(t, u], w}\right)$ for all $w \in \mathrm{OP}_{t}$

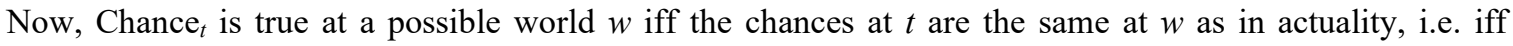
$\operatorname{ch}_{t, w}(\mathrm{P})=\operatorname{ch}_{t}(\mathrm{P})$ and $\operatorname{ch}_{t, w}(\mathrm{P} \mid \mathrm{Q})=\operatorname{ch}_{t}(\mathrm{P} \mid \mathrm{Q})$ for all claims $\mathrm{P}$ and $\mathrm{Q}$. Consequently:

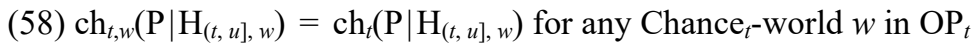

By (57) and (58), $\operatorname{ch}_{u, w}(\mathrm{P})=\operatorname{ch}_{t}\left(\mathrm{P} \mid \mathrm{H}_{t, u], w}\right)$ for any Chance - world $w$ in $\mathrm{OP}_{t}$. Hence, $\mathrm{Ch}_{u, w}(\mathrm{P})$ and

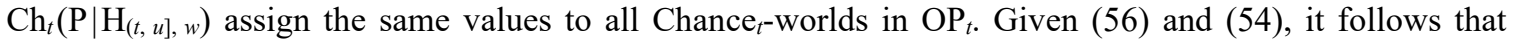
$\mathrm{Ch}_{u, w}(\mathrm{P})$ is an extension of $\mathrm{Ch}_{t}\left(\mathrm{P} \mid \mathrm{H}_{(t, u], w}\right)$, so that

(59) $\mathrm{E}_{\mathrm{ch}_{t}}\left(\mathrm{Ch}_{u, w}(\mathrm{P})\right)=\mathrm{E}_{\mathrm{ch}_{t}}{ }^{*}\left(\mathrm{Ch}_{t}\left(\mathrm{P} \mid \mathrm{H}_{(t, u], w}\right)\right)$ 
(19) Necessarily, if $t<u$, then the chance distribution at $u$ comes from the chance distribution at $t$ by conditionalizing on the complete truth about post- $t$ history up to $u .^{14}$

Examples of undermining can violate ECP, however. To see that this is true of MPCgenerated undermining cases, it is best to note first that these cases can violate the following diachronic variant of $\mathbf{4}_{t}^{\text {ch }}$ (stated below in symbols and in words).

$$
\begin{aligned}
& \mathbf{4}_{t, u}^{\text {ch }} \quad \diamond_{t}^{\text {ch }} \diamond_{u}^{\text {ch }} \mathrm{P} \rightarrow \diamond_{t}^{\text {ch }} \mathrm{P}, \text { whenever } t<u \\
& \text { If } t<u \text { and } \operatorname{ch}_{t}\left(\operatorname{ch}_{u}(\mathrm{P})>0\right)>0 \text {, then } \operatorname{ch}_{t}(\mathrm{P})>0 .
\end{aligned}
$$

Given standard assumptions about probability (including countable additivity), ECP can be shown to entail that $\mathbf{4}_{t}^{\text {ch }}$ holds for any claim $\mathrm{P}$ and times $t$ and $u$ for which $\mathrm{E}_{\mathrm{ch}_{t}}\left(\mathrm{Ch}_{u, w}(\mathrm{P})\right)$

(55) and (59) entail that $\operatorname{ch}_{t}(\mathrm{P})=\mathrm{E}_{\mathrm{ch}_{t}}\left(\mathrm{Ch}_{u, w}(\mathrm{P})\right)$. Discharging assumptions (53) and (54), we obtain the following principle.

ECP: $\quad \operatorname{ch}_{t}(\mathrm{P})=\mathrm{E}_{\mathrm{ch}_{t}}\left(\mathrm{Ch}_{u, w}(\mathrm{P})\right)$ whenever $t<u$, provided $\mathrm{E}_{\mathrm{ch}_{t}}\left(\mathrm{Ch}_{u, w}(\mathrm{P})\right)$ is defined

${ }^{14}$ The complete truth about the post- $t$ history up to $u$ could have a chance of zero at $t$ (in particular if there are infinitely many ways this stretch of history could have unfolded consistently with the history up to $t$ and the laws). (19) therefore assumes that it is possible to conditionalize on zero-probability claims, which in turn is inconsistent with defining conditional probabilities as ratios. To me that seems unproblematic, as I think that there are strong independent reasons for thinking that it is possible to conditionalize on zero-probability claims and that the ratio definition of conditional probabilities should therefore be rejected. (See Hájek 2011, Sect. 4 for an exposition of some of the problems for the ratio definition.) We can instead avail ourselves of one of the theories that view the notion of conditional probability as primitive, such as the theory proposed by Rényi (1970). 
is defined. ${ }^{15,16}$ When $\mathrm{E}_{\mathrm{ch}_{t}}\left(\mathrm{Ch}_{u, w}(\mathrm{P})\right)$ is undefined, ECP does not apply-it simply falls silent - and so ECP does not entail that $\mathbf{4}_{t, u}^{\text {ch }}$ holds in such cases.

Nevertheless, it seems very plausible that $\mathbf{4}_{t, u}^{\text {ch }}$ is true in such cases, for $\mathbf{4}_{t, u}^{\text {ch }}$ is simply very compelling: if there is some (positive) chance now that there will some chance tomorrow that we will win next week, then there is some chance now that we will win.

MPC-ists have to deny that $\mathbf{4}_{t, u}^{\text {ch }}$ is true of Example 1. At $w_{1}, \mathrm{BCD}_{\mathrm{W}}$ is true and $\mathrm{CDE}_{\mathrm{W}}$ is therefore metaphysically possible. Moreover,

\footnotetext{
${ }^{15}$ This can be shown using Markov's Inequality: $\mathrm{E}_{p}(\mathrm{X}) \geq a \times p(\mathrm{X} \geq a)$, where $\mathrm{X}$ is a non-negative random variable whose expectation relative to the probability function $p$ is $\mathrm{E}_{p}(\mathrm{X})$.

Assume that ECP is true. Moreover, suppose the following:
}

(60) $\mathrm{E}_{\mathrm{ch}_{t}}\left(\mathrm{Ch}_{u, w}(\mathrm{P})\right)$ is defined.

(61) $t<u$

(62) $\operatorname{ch}_{t}\left(\operatorname{ch}_{u}(\mathrm{P})>0\right)>0$

Let $Z^{+}$be the set of positive integers, and for any $i \in Z^{+}$, let $\mathrm{I}(i)$ be the half-open interval $(1 / i+1,1 / i]$. The following claims are clearly true.

(63) $\mathrm{I}(i) \cap \mathrm{I}(j)=\varnothing$ if $i \neq j$

(64) $\bigcup_{i \in Z^{+}} \mathrm{I}(i)=(0,1]$

Now assume the following for reductio:

(65) $\operatorname{ch}_{t}\left(\mathrm{ch}_{u}(\mathrm{P}) \in \mathrm{I}(i)\right)=0$ for all $i \in Z^{+}$

Given the assumption that probabilities are countably additive, it follows from (63)-(65) that $\operatorname{ch}_{t}\left(\operatorname{ch}_{u}(\mathrm{P}) \in(0,1]\right)=0$ and hence that $\operatorname{ch}_{t}\left(\operatorname{ch}_{u}(\mathrm{P})>0\right)=0$, which contradicts (62). So, (65) is false. Hence, for some $k \in Z^{+}, \operatorname{ch}_{t}\left(\operatorname{ch}_{u}(\mathrm{P}) \in \mathrm{I}(k)\right)>0$. It follows that $\operatorname{ch}_{t}\left(\operatorname{ch}_{u}(\mathrm{P})>1 / k+1\right)>0$, which in turn entails (66) below. (67) can be inferred from Markov's Inequality. ECP, (60), and (61) entail (68).

(66) $1 / k+1 \operatorname{ch}_{t}\left(\mathrm{Ch}_{u, w}(\mathrm{P})>1 / k+1\right)>0$

(67) $\mathrm{E}_{\mathrm{ch}_{t}}\left(\mathrm{Ch}_{u, w}(\mathrm{P})\right) \geq 1 /{ }_{k+1} \operatorname{ch}_{t}\left(\mathrm{Ch}_{u, w}(\mathrm{P}) \geq 1 / k+1\right) \geq 1 / k+1 \operatorname{ch}_{t}\left(\mathrm{Ch}_{u, w}(\mathrm{P})>1 / k+1\right)$

$(68) \operatorname{ch}_{t}(\mathrm{P})=\mathrm{E}_{\mathrm{ch}_{t}}\left(\mathrm{Ch}_{u, w}(\mathrm{P})\right)$

(66) and (67) entail that $\mathrm{E}_{\mathrm{ch}_{t}}\left(\mathrm{Ch}_{u, w}(\mathrm{P})\right)>0$, which together with (68) entails that $\operatorname{ch}_{t}(\mathrm{P})>0$. Discharging assumptions (61) and (62), we get: if $t<u$ and $\operatorname{ch}_{t}\left(\operatorname{ch}_{u}(\mathrm{P})>0\right)>0$, then $\operatorname{ch}_{t}(\mathrm{P})>0$. In other words, $4_{t u}^{\text {ch }}$ is true for $\mathrm{P}, t$ and $u$. Discharging (60), we can conclude: if $\mathrm{E}_{\mathrm{ch}_{t}}\left(\mathrm{Ch}_{u, w}(\mathrm{P})\right)$ is defined, then $\mathbf{4}_{t, u}^{\mathrm{ch}}$ is true for $\mathrm{P}, t$ and $u$. 16 The diachronic variant of $\boldsymbol{5}_{t, u}^{\text {ch }}$ runs as follows: $\diamond_{u}^{\text {ch }} \mathrm{P} \rightarrow \square_{t}^{\text {ch }} \diamond_{u}^{\text {ch }} \mathrm{P}$ whenever $t<u$. In other words: if $\operatorname{ch}_{u}(\mathrm{P})>0$, then $\operatorname{ch}_{t}\left(\operatorname{ch}_{u}(\mathrm{P})>0\right)=1$ whenever $t<u$. That principle is not entailed by ECP, and it is clearly false: It could be that the present chance that $\mathrm{P}$ is positive, but that there was some positive chance yesterday that the chance that $\mathrm{P}$ would sink to zero (and then stay at zero) before the present. 


$$
\text { At } w_{1}, \operatorname{ch}_{u}\left(\mathrm{CDE}_{\mathrm{W}}\right)=1 / 2
$$

Given that $\operatorname{ch}_{t}\left(\left\{w_{1}\right\}\right)>0$, we can use (20) and the Modality-Chance Principle (MC) to infer that $\operatorname{ch}_{t}\left(\operatorname{ch}_{u}(\mathrm{CDE})>0\right)>0$. And yet, since $\mathrm{CDE}_{\mathrm{W}}$ is actually impossible, actually $\operatorname{ch}_{t}\left(\mathrm{CDE}_{\mathrm{W}}\right)=0$. That violates $\mathbf{4}_{t, u}^{\mathrm{ch}}$. By the same token, ECP is violated as well: $\mathrm{E}_{\mathrm{ch}_{t}}\left(\mathrm{Ch}_{u, w}\left(\mathrm{CDE}_{\mathrm{W}}\right)\right)=1 / 4 \neq 0=\mathrm{ch}_{t}\left(\mathrm{CDE}_{\mathrm{W}}\right) .{ }^{17}$ Hence, MPC-ists have to deny both $\mathbf{4}_{t, u}^{\mathrm{ch}}$ and ECP. ${ }^{18}$

\subsection{The logic of open possibility}

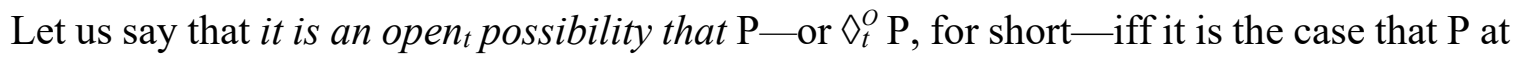
some world in the sample space of the chance distribution at $t$, that is, iff the claim that $\mathrm{P}$ is compossible with the history through $t$ and the laws. Moreover, let us say that it is settled

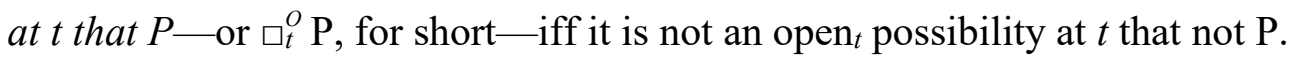

' $\nabla_{t}^{o}$ ' is weaker than ' $\nabla_{t}^{\mathrm{ch}}$. The truth of ' $\nabla_{t}^{o} \mathrm{P}$ ' requires merely that the class of open possibilities where $\mathrm{P}$ be non-empty. The truth of ' $\nu_{t}^{\text {ch }} \mathrm{P}$ ' requires in addition that this class have a positive chance measure at $t$. The first condition is satisfied without the second in examples like the following. You are throwing a dart with a point-sized (infinitely small) tip at a dartboard. For any point $p$ on the dartboard, the past and the laws leave open that you will hit $p$, so that $\mho_{t}^{o}$ You will hit $p$. Moreover, the chance density is constant over all locations on the dartboard (i.e., measurable regions of the same size have the same chance of being hit). Hence, for any point $p$ on the board, $\operatorname{ch}_{t}($ You will hit $p)=0$, so that $\neg \diamond_{t}^{\text {ch }}$ (You will hit $p$ ).

We can formulate both a synchronic and a diachronic S4-principle for for ' $\nabla_{t}^{O}$ ':

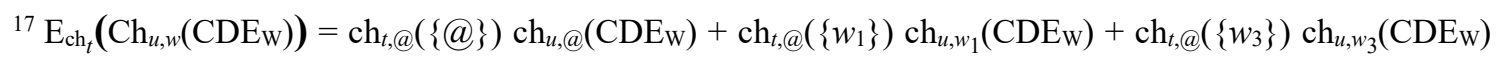
$=1 / 2 \times 0+1 / 4 \times 1 / 2+1 / 4 \times 1 / 2=1 / 4$.

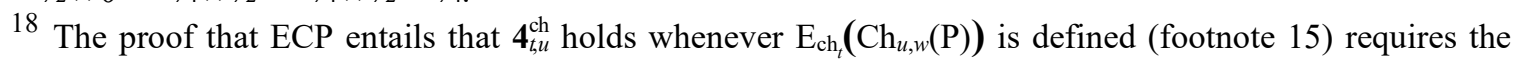
principle of countable additivity. While this is a standard assumption and one of Kolmogorov's axioms, some philosophers have denied the principle (De Finetti 1972, also see Howson 2008). Such philosophers might reject $\mathbf{4}_{t, u}^{\text {ch }}$. (Those who take De Finetti lotteries to be possible can construct a counterexample. Suppose we decide to draw a positive integer by a De Finetti lottery just after $t$ (but before $u$ ) and then to arrange things so that $\operatorname{ch}_{u}(\mathrm{P})=1 / i$, where $i$ is the integer we drew. Then $\operatorname{ch}_{t}\left(\operatorname{ch}_{u}(\mathrm{P})>0\right)=1>0 . \mathrm{Yet} \operatorname{ch}_{t}\left(\operatorname{ch}_{u}(\mathrm{P})<p\right)=1$ for all $p>0$, from which it seems to follow that $\operatorname{ch}_{t}(\mathrm{P})=0$.) But even those who deny countable additivity have no reason to deny the weaker principle $\mathbf{4}_{t, u}^{\text {ch- }}$ stated below. For, countable additivity is not needed to show that ECP entails that $4_{t, u}^{\mathrm{ch}-}$ holds whenever $\mathrm{E}_{\mathrm{ch}_{t}}\left(\mathrm{Ch}_{u, w}(\mathrm{P})\right)$ is defined (the proof is similar to the one given in footnote $15)$.

$\mathbf{4}_{t, u}^{\text {ch- }} \quad$ If $t<u$ and $\operatorname{ch}_{t}\left(\operatorname{ch}_{u}(\mathrm{P}) \geq p\right)>0$ for some $p>0$, then $\operatorname{ch}_{t}(\mathrm{P})>0$.

$\mathbf{4}_{t, u}^{\mathrm{ch}-}$ is very compelling. Moreover, the example that was used to show that MPC violates $\mathbf{4}_{t, u}^{\mathrm{ch}}$ also shows that MPC violates $\mathbf{4}_{t, u}^{\mathrm{ch}-}$. Denying countable additivity therefore does not help MPC-ists. 


$$
\begin{aligned}
& \mathbf{4}_{t}^{O} \quad \diamond_{t}^{O} \diamond_{t}^{O} \mathrm{P} \rightarrow \diamond_{t}^{O} \mathrm{P} \\
& \mathbf{4}_{t, u}^{O} \diamond_{t}^{O} \diamond_{u}^{O} \mathrm{P} \rightarrow \diamond_{t}^{O} \mathrm{P} \quad \text { whenever } t<u
\end{aligned}
$$

Both principles seem very compelling. If it is an open possibility now that it is an open possibility now that we will win the game next weekend, then it is an open possibility now that we will win (i.e., then it cannot already be settled now that we will not win). Similarly, if it is an open possibility now that it will be an open possibility tomorrow, then it is an open possibility now. The synchronic version of the S5-principle for the new operators seems plausible as well:

$$
\mathbf{5}_{t}^{O} \quad \diamond_{t}^{O} \mathrm{P} \rightarrow \square_{t}^{o} \diamond_{t}^{O} \mathrm{P}
$$

If it is an open possibility now that we will win, then it is settled now that that is now an open possibility. ${ }^{19}$

$\mathbf{4}_{t}^{O}, \mathbf{4}_{t, u}^{O}$, and $\mathbf{5}_{t}^{O}$ are logically independent of the principles previously discussed. This should be unsurprising, since the one group of principles differs somewhat from the other in subject matter. The three principles about open possibility essentially tells us that the sample space of the actual chance distribution at $t$ is related in a certain way to the sample spaces of the chance distributions (at $t$ or at later times) at other open ${ }_{t}$ possibilities. (For example, $\mathbf{4}_{t}^{O}$ and $\mathbf{4}_{t, u}^{O}$ together tell us that if one of the latter sample spaces includes a Pworld, then so does the former.) But the three principles say nothing about how chances are distributed over these sample spaces at the actual world or at the other open ${ }_{t}$ possibilities. The opposite is true of the principles discussed in $\S \S 3.2-3.3$. They are about the chance distributions (at $t$ and at later times) at the actual world and at other open $t$ possibilities. But they have only minimal implications about the way in which the sample spaces of these chance distributions are related to each other. In particular, they do not entail $\mathbf{4}_{t}^{O}, \mathbf{4}_{t, u}^{O}$, or $\mathbf{5}_{t}^{O}{ }^{20}$

Example 1 can be used to show that MPC violates $\mathbf{4}_{t}^{O}, \mathbf{4}_{t, u}^{O}$, and $\mathbf{5}_{t}^{O}$. I will focus on $\mathbf{4}_{t, u}^{O}$, but similar arguments could be used to show that $\mathbf{4}_{t}^{O}$ and $\mathbf{5}_{t}^{O}$ are violated as well. At the actual world, it is compossible with history through $t$ and the laws that $w_{1}$ will be actualized. Similarly, at $w_{1}$ it is compossible with history through $u$ and the laws that CDEW. So, at the actual world, $\diamond_{t}^{o} \diamond_{u}^{O} \mathrm{CDE}_{\mathrm{W}}$. And yet, actually $\neg \nabla_{t}^{O} \mathrm{CDE}$, since actually $\neg \diamond \mathrm{CDE}_{\mathrm{W}}$. That violates $\mathbf{4}_{t, u}^{O}$.

\footnotetext{
${ }^{19}$ The diachronic S5-principle for ' $\vee_{t}^{O}$ ' is clearly unacceptable. It runs thus: $\diamond_{u}^{O} \mathrm{P} \rightarrow \square_{t}^{O} \diamond_{u}^{O} \mathrm{P}$ whenever $t<u$. Contrary to this principle, it might be that it is an open possibility now that $\mathrm{P}$, but that it was not settled yesterday that it would still be an open possibility now that $P$.

${ }^{20}$ This non-entailment claim is a corollary of one of the findings of $\S 3.5$, namely the result that some views are consistent with the principles discussed in $\S \S 3.2-3.3$ but not with $\mathbf{4}_{t,}^{O}, \mathbf{4}_{t, u}^{O}$, or $\mathbf{5}_{t}^{O}$.
} 


\subsection{Possible responses by non-counterpart-theoretic MPC-ists}

I will consider two MPC-ist strategies for addressing the problems outlined in §§3.2-3.4.

The first strategy is to say that under indeterminism the modal facts can vary over time. The principle Necessity of $\S 2$ should be restricted: it states constraints on what is possible for a table that apply at a given time only if it is already settled at that time which parts the table will be made from. In Example 1, CDEw is metaphysically possible at time $t$ (before the coin has landed on the first toss). Once the coin has landed heads, so that it is settled that Woody will be made from $\mathrm{ABC}$, Necessity kicks in and $\mathrm{CDE}_{\mathrm{W}}$ becomes metaphysically impossible. $\left(\mathrm{BCD}_{\mathrm{W}}\right.$ remains metaphysically possible, even if it is no longer an open possibility that $\mathrm{BCD}_{\mathrm{w}}$.) The sample space of the chance distribution $\mathrm{ch}_{t}$ is a class of worlds that are metaphysically possible at $t$ (but some of which might become

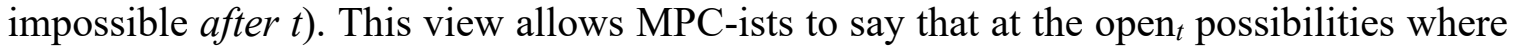
a table is made from CDE, the table is Woody, so that the following holds at the actual world:

(21) $\operatorname{ch}_{t}\left(\mathrm{CDE}_{\mathrm{W}}\right)=1 / 4$

Since (21) also holds at the other open $t_{t}$ possibilities, it follows that actually, $\operatorname{ch}_{t}\left(\operatorname{ch}_{t}\left(\mathrm{CDE}_{\mathrm{W}}\right)=1 / 4\right)=1$. Consequently, the chance at $t$ is zero that the chance of CDEW at $t$ is different from what it actually is. The chances at $t$ do not undermine themselves. By the same manoeuvre, MPC-ists also prevent violations of ECP$\mathrm{E}_{\mathrm{ch}_{t}}\left(\mathrm{Ch}_{u, w}\left(\mathrm{CDE}_{\mathrm{W}}\right)\right)=1 / 4=\mathrm{ch}_{t}\left(\mathrm{CDE}_{\mathrm{W}}\right)$, just as ECP predicts—and consequently of $\mathbf{4}_{t, u}^{\mathrm{ch}}$. Their view becomes consistent with $\mathbf{4}_{t,}^{o} \mathbf{4}_{t, u}^{o}$, and $\mathbf{5}_{t}^{o}$ as well, as I will show for the case of $\mathbf{4}_{t, u}^{o}$. For any possible world $w$, let $\mathrm{H}_{t, w}$ be the complete truth about the history up to $t$ as it is at $w$ and let $\mathrm{L}_{w}$ be the conjunction of $w$ 's laws of nature. The MPC-ist can say: it is true at a possible world $w$ that $\vartheta_{t}^{o} \mathrm{P}$ iff the conjunction of the claim that $\mathrm{P}$ with $\mathrm{H}_{t, w}$ and $\mathrm{L}_{w}$ is metaphysically possible at time $t$. (It does not matter whether the conjunction is possible at later times.) By this definition, it is actually true that $\vartheta_{t}^{o} \mathrm{CDE}_{\mathrm{W}}$. This avoids the counterexample to $\mathbf{4}_{t, u}^{o}$ described in the previous section.

A thorough evaluation of this dynamic conception of modal space is beyond the scope of this paper. Suffice it to say that relativizing metaphysical necessity and possibility to a time amounts to a significant shift in the way we think about modality. Without an independent motivation for this change, it seems $a d$ hoc to propose such a major conceptual revision to save MPC from problematic consequences.

A second strategy for solving the problems for MPC is to give up the thesis I called

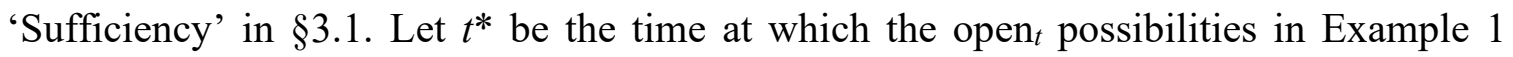
diverge from each other. Denying Sufficiency allows MPC-ists to say that in Example 1 there is no combination of (i) (qualitative and non-qualitative) truths about history before $t^{*}$ and (ii) other qualitative truths, such that (i) and (ii) metaphysically necessitate that if a 
table is made from BCD, then that table is Woody. MPC-ists who hold that all laws are qualitative truths can infer that the history before $t^{*}$ and the laws together do not necessitate that any table made from BCD is Woody. In other words, contrary to what I assumed in my discussion in $\S \S 3.2-3.4$, the open ${ }_{t}$ possibilities include not only worlds where Woody is made from $\mathrm{BCD}$, but also worlds where a table other than Woody is made from BCD. The assumption that $\mathrm{ch}_{t}(\mathrm{~A}$ table will be made from $\mathrm{BCD})=1 / 4$ consequently does not force MPC-ists to say that $\operatorname{ch}_{t}\left(\mathrm{BCD}_{\mathrm{W}}\right)>0$. They can say instead that there is a $1 / 4$ chance at $t$ that a table other than Woody will be made from BCD, and that the class of open ${ }_{t}$ possibilities where Woody is made from $\mathrm{BCD}$ (while non-empty) has a chance measure of zero at $t$. (By analogous reasoning, they can say that at open ${ }_{t}$ possibilities where $B C D_{w}$ holds, $\operatorname{ch}_{t}\left(C \mathrm{DEW}_{\mathrm{w}}\right)$ $=0$. That would vitiate the arguments from MPC to the claim that Example 1 is a case of undermining and to the conclusion that it violates ECP and $\mathbf{4}_{t, u}^{\mathrm{ch}}$.

One would of course like to be given some independent reason for thinking that $\mathrm{ch}_{t}(\mathrm{BCD})$ must equal zero in the example. But even if such a reason can be given, it should be clear that the MPC-ist response just sketched does not allow MPC-ists to avoid violations of $\mathbf{4}_{t}^{o} \mathbf{4}_{t, u}^{o}$, or $\mathbf{5}_{t}^{O}$. I will consider $\mathbf{4}_{t, u}^{o}$ for the sake of illustration (the cases of $\mathbf{4}_{t}^{o}$ and $\mathbf{5}_{t}^{O}$ are analogous). Irrespective of their attitude towards Sufficiency, their commitment to

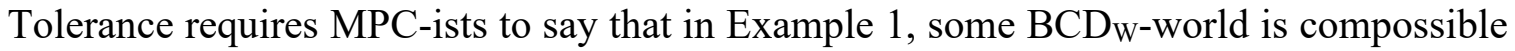
with the history up to $t$ and the laws, and that at this $\mathrm{BCD}_{\mathrm{W}}$-world, $\mathrm{CDE}_{\mathrm{W}}$ is compossible with history up to $u$ and the laws. Consequently, it is actually an open ${ }_{t}$ possibility that it

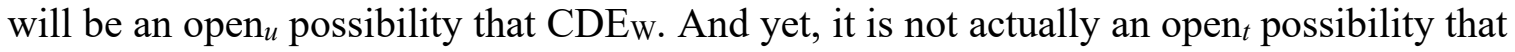
$\mathrm{CDE}_{\mathrm{W}}$. That violates $\mathbf{4}_{t, u}^{o}$.

In any case, the strategy of avoiding the difficulties for MPC by denying Sufficiency comes at a significant cost — as noted in §3.1, denying Sufficiency amounts to a strong and (I think) implausible commitment.

\section{Counterpart-theoretic MPC}

Counterpart theorists analyze de re modal claims by appealing to a counterpart relation between individuals at different possible worlds (see, e.g., Lewis 1968, 1986a, Ch. 4, Fara 2009). The simplest version of counterpart theory tells us this: ${ }^{21}$

$\diamond \mathrm{F} a$ at $w$ iff some possible world $w^{*}$ contains a counterpart $a^{*}$ of $a$ such that $\mathrm{F} a^{*}$.

\footnotetext{
${ }^{21}$ There are somewhat different versions of counterpart theory on the market (see Fara and Williamson 2005 and Russell 2013 for partial overviews). However, with the exception of the distinction between qualitative and non-qualitative counterpart theory described below, the differences do not matter to the points I want to make.
} 
Counterpart theorists can explain facts about the modal profiles of individuals by appealing to features of the counterpart relation. For example, they can explain the fact that Socrates could not have been a fried egg by saying that two objects need to meet certain minimum standards of mutual similarity to count as counterparts, and that a fried egg and a human being do not meet those standards.

De re modal claims involving polyadic relations are somewhat more complex. The simplest counterpart-theoretic account entails the following (' $\mathrm{R}$ ' is a placeholder for an $n$ place predicate, and ' $a$ ', ' $b$ ', $\ldots$, ' $n$ ' refer to individuals existing at $w$ ):

(22) $\diamond \mathrm{R} a b \ldots n$ at $w$ iff some possible world $w^{*}$ contains counterparts $a^{*}, b^{*}, \ldots, n^{*}$ of $a, b, \ldots, n$, respectively, such that $\mathrm{R}^{*} b^{*} \ldots n^{*}$.

(And of course, $\diamond \mathrm{R} a b \ldots n$ iff at the actual world, $\diamond \mathrm{R} a b \ldots n$.) However, this account does not quite work as it stands (Hazen 1979). Counterpart theorists typically want to allow for a possible world $w_{2 \mathrm{BO}}$ that contains two counterparts, $j_{1}$ and $j_{2}$, of Barack Obama Jr. and two counterparts, $s_{1}$ and $s_{2}$, of his father, Barack Obama Sr., with $j_{1}$ being $s_{1}$ 's son and $j_{2}$ being $s_{2}$ 's. Since $j_{1}$ is the son of someone other than $s_{2}$, it is true that at $w_{2}$ Bо there exist counterparts $x$ and $y$ of Obama Jr. and Obama Sr., respectively, such that $x$ is the son of someone other than $y$. Therefore, the following is true according to (22):

(23) Possibly, Obama Jr. is the son of someone other than Obama Sr.

That seems wrong.

Counterpart theorists can avoid this result if they assign truth-conditions to sentences of the form $\diamond \mathrm{R} a b \ldots n$ by appealing to counterparts not of $a, b, \ldots, n$ taken individually, but of the ordered $n$-tuple $<a, b, \ldots, n>$ (Hazen 1979, Lewis 1986a, pp. 232-3). For one $n$ tuple to be a counterpart of another, it is not enough that each member of the first $n$-tuple stands in the right similarity relation to the corresponding member of the second. It is required in addition that the members of the one $n$-tuple be related to each other in ways sufficiently similar to the ways in which the members of the other $n$-tuple are related. There are different versions of this account (and the choice between them is not entirely trivial). For definiteness, I will work with a variant that appeals to what I will call 'counterpart functions', though my arguments equally apply (mutatis mutandis) to other versions. A counterpart function is a partial function $f_{w^{*}, w}$ from the objects at one possible world $w^{*}$ to the objects at another possible world $w$ that meets certain constraints that the counterpart theorist needs to specify. Importantly, it needs to meet the following condition (among others): whenever $f_{w^{*}, w}$ maps certain objects at $w^{*}$ to certain objects at $w$, the way in which the former objects are related to each other is sufficiently similar (in the right respects) to the way in which the latter objects are related to one another. For example, since Obama 


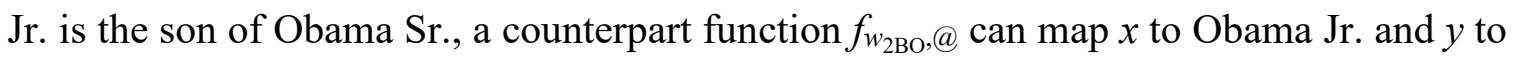
Obama Sr. only if $x$ is the child of $y$. I will call this the 'relational constraint' on counterpart functions. Counterparthood can be defined in terms of counterpart functions: $y$ at $w^{*}$ is a counterpart of $x$ at $w$ iff some counterpart function $f_{w^{*}, w}$ maps $y$ to $x$. An $n$-tuple $<y_{1}, y_{2}, \ldots, y_{n}>$ of objects at $w^{*}$ is a counterpart of an $n$-tuple $<x_{1}, x_{2}, \ldots, x_{n}>$ of objects at $w$ iff some counterpart function $f_{w^{*}, w}$ maps $y_{1}$ to $x_{1}, y_{2}$ to $x_{2}, \ldots$, and $y_{n}$ to $x_{n}$. (Note that there can be different counterpart functions from one world $w^{*}$ to another world $w$. Consequently, different objects ( $n$-tuples of objects) at $w^{*}$ can be counterparts of a single object ( $n$-tuple of objects) at $w$.) Finally:

(24) $\diamond \mathrm{R} a b \ldots n$ at $w$ iff some possible world $w^{*}$ contains individuals $a^{*}, b^{*}, \ldots, n^{*}$ such that $<a^{*}, b^{*}, \ldots, n^{*}>$ is a counterpart of $<a, b, \ldots, n>$ and $\mathrm{R} a^{*} b^{*} \ldots n^{*}$.

The relational constraint on counterpart functions ensures that in our earlier example of $w_{2 \mathrm{BO}}$, the counterparts of $<$ Obama Jr., Obama Sr. $>$ can include neither $<j_{1}, s_{2}>$ nor $<j_{2}, s_{1}>$, though they may include $<j 1_{1}, s_{1}>$ and $<j_{2}, s_{2}>$. Counterpart theorists who endorse (24) can therefore avoid commitment to (23).

Iterated modal claims can be explained along similar lines:

(25) $\diamond \diamond \mathrm{R} a b \ldots n$ at $w$ iff some possible world $w^{*}$ contains individuals $a^{*}, b^{*}, \ldots, n^{*}$ such that $<a^{*}, b^{*}, \ldots, n^{*}>$ is a counterpart of $<a, b, \ldots, n>$ and $\diamond \mathrm{R} a^{*} b^{*} \ldots n^{*}$ at $w^{*}$.

(24) and (25) do not amount to a general counterpart-theoretic account of de re modal claims, since they only yield truth-conditions for sentences formed by prefixing one or more possibility operators to an atomic sentence. However, that will suffice for the points I want to make.

The modality-chance principle can also be reformulated to obtain a counterparttheoretic account of de re chance ascriptions. Again, I will not try to give a general such account, but will restrict my attention to the special cases that matter to this discussion (the

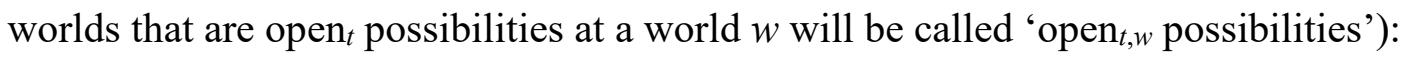

(26) (i) $\operatorname{ch}_{t}(\operatorname{R} a b \ldots n)=p$ at $w$ iff $\operatorname{ch}_{t, w}$ assigns $p$ to the class of all open ${ }_{t, w}$ possibilities $w^{*}$ such that, for some individuals $a^{*}, b^{*}, \ldots, n^{*}$ at $w^{*},<a^{*}, b^{*}, \ldots, n^{*}>$ is a counterpart of $<a, b, \ldots, n>$ and $\mathrm{R} a^{*} b^{*} \ldots n^{*}$.

(ii) $\operatorname{ch}_{t}\left(\operatorname{ch}_{u}(\operatorname{Rab} \ldots n)=p\right)=q$ at $w$ iff $\operatorname{ch}_{t, w}$ assigns $q$ to the class of all $\operatorname{open}_{t, w}$ possibilities $w^{*}$ such that, for some individuals $a^{*}, b^{*}, \ldots, n^{*}$ at $w^{*}$, $<a^{*}, b^{*}, \ldots, n^{*}>$ is a counterpart of $<a, b, \ldots, n>$ and $\operatorname{ch}_{u}\left(\operatorname{R} a^{*} b^{*} \ldots n^{*}\right)=p$ at $w^{*}$. 
Counterpart-theoretic MPC-ists can explain why (3) and (4) hold by endorsing some principles along the following lines:

Necessity ${ }_{C P}$ : Where $x$ is any table at any possible world $w$ and the $y$ s are $x$ 's parts, if a counterpart function $f_{w^{*}, w}$ maps an object $x^{*}$ at some possible world $w^{*}$ to $x$, then $f_{w^{*}, w}$ maps parts of $x^{*}$ to at least $2 / 3$ of the $y \mathrm{~s}$.

Tolerance ${ }_{C P}$ : Where $x$ is any table at any possible world $w$, the $y$ s are $x$ 's parts, and the $z$ s include $2 / 3$ of the $y$ s (and nothing else), there is a counterpart function $f_{w^{*}, w}$ that maps an object $x^{*}$ at some possible world $w^{*}$ to $x$ while mapping $x^{*}$ 's parts to the $z \mathrm{~s}$ and to some suitable other objects that are not among the $y \mathrm{~s}$.

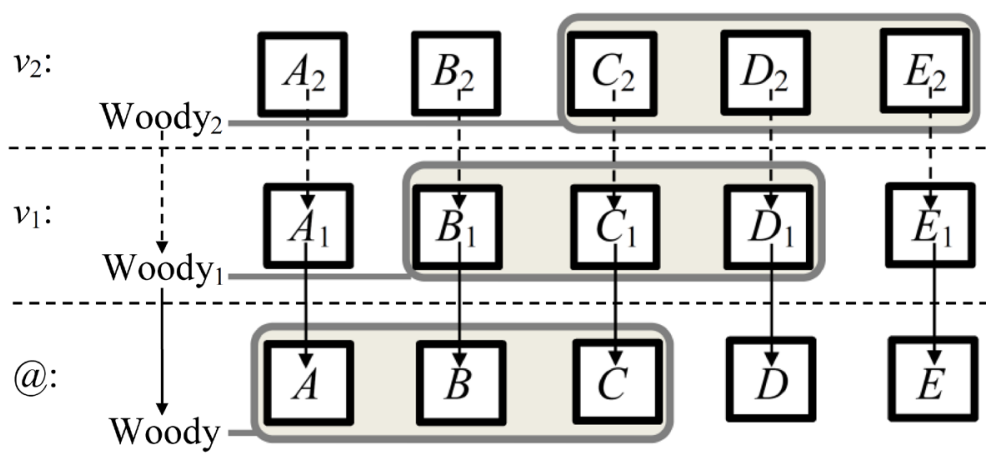

Figure 3. Counterpart-theoretic MPC-ist explanation of counterexamples to 4 .

Counterpart theorists who endorse these principles can explain what is going on in the counterexamples to $\mathbf{4}$ and $\mathbf{5}$ discussed in $\S 2$. Some possible world $v_{1}$ contains five blocks of wood $\mathrm{A}_{1}-\mathrm{E}_{1}$ and a table Woody 1 made from $\mathrm{B}_{1} \mathrm{C}_{1} \mathrm{D}_{1}$, such that some counterpart function maps $\mathrm{A}_{1}$ to $\mathrm{A}, \mathrm{B}_{1}$ to $\mathrm{B}, \ldots$, and Woody $\mathrm{W}_{1}$ to Woody. (In Figure 3, a solid arrow from one individual to another indicates that this function maps the first individual to the second.) There is also a possible world $v_{2}$ that contains five blocks of wood $\mathrm{A}_{2}-\mathrm{E}_{2}$ and a table Woody 2 made from $\mathrm{C}_{2} \mathrm{D}_{2} \mathrm{E}_{2}$, such that some counterpart function maps $\mathrm{A}_{2}$ to $\mathrm{A}_{1}, \mathrm{~B}_{2}$ to $\mathrm{B}_{1}, \ldots$, and Woody 2 to Woody $\mathrm{W}_{1}$ (This mapping is represented by the dashed arrows.) By (24), it is true at $v_{1}$ that $\diamond$ Woody $_{1}$ is made from $\mathrm{C}_{1} \mathrm{D}_{1} \mathrm{E}_{1}$, from which it follows by (25) that the following actually holds:

(27) $\diamond \diamond$ Woody is made from CDE

While $<$ Woody $_{2}, \mathrm{~A}_{2}, \mathrm{~B}_{2}, \mathrm{C}_{2}, \mathrm{D}_{2}, \mathrm{E}_{2}>$ is a counterpart of $<$ Woody $_{1}, \mathrm{~A}_{1}, \mathrm{~B}_{1}, \mathrm{C}_{1}, \mathrm{D}_{1}, \mathrm{E}_{1}>$ and $<\mathrm{A}_{1}, \mathrm{~B}_{1}, \mathrm{C}_{1}, \mathrm{D}_{1}, \mathrm{E}_{1}$, Woody $>$ is a counterpart of $<\mathrm{A}, \mathrm{B}, \mathrm{C}, \mathrm{D}, \mathrm{E}$, Woody $>$, NecessitycP ensures that $<A_{2}, B_{2}, C_{2}, D_{2}, E_{2}$, Woody $2>$ is not a counterpart of $<A, B, C, D, E$, Woody $>$. 
(Counterparthood is not transitive.) Moreover, since actually $\mathrm{ABC}_{\mathrm{W}}$, Necessity $\mathrm{CP}_{\mathrm{P}}$ guarantees that no counterpart function maps any table $\mathrm{T}$ in any possible world that is made from three parts to Woody while mapping T's parts to C, D, and E. Combined with (24), that guarantees that

(28) $\neg \vartheta$ Woody is made from CDE

(27) and (28) constitute a counterexample to 4 . Counterexamples to 5 can be explained in a similar way.

I will argue that counterpart theory does not put MPC-ists in a position to avoid the problems discussed in $\S \S 3.2-3.4$. But first, I have to distinguish between two versions of counterpart theory that require somewhat different treatments. The two views differ on the question, 'Do the qualitative features of two worlds determine which objects at the one world are counterparts of which objects at the other?'. A qualitative counterpart theorist will answer 'yes', while a non-qualitative counterpart theorist will say 'no'. While most counterpart theorists have followed David Lewis in endorsing the first view, the second position has also been held (Fara 2009). I will discuss qualitative counterpart theory first, before turning to the non-qualitative version.

Qualitative counterpart theorists endorsing Necessity ${ }_{C P}$ and Tolerance ${ }_{C P}$ have to say that schema (29) has true instances and are therefore committed to the possibility of undermining.

$$
\operatorname{ch}_{t}(\mathrm{P})=x \quad \& \quad \operatorname{ch}_{t}\left(\neg \operatorname{ch}_{t}(\mathrm{P})=x\right)>0 .
$$

To see this, note first that qualitative counterpart theory entails the following: where $x$ is any individual or any $n$-tuple of individuals that inhabit the same world, there is some (possibly partly extrinsic) qualitative condition - call it ' $\mathrm{Cond}_{x}$ ' - that is necessary and sufficient for any object at any possible world to be a counterpart of $x$. Now consider Example 1 again, and suppose that things have been set up so that there are exactly three open $_{t}$ possibilities. Firstly, the world @, at which A-E exist and Woody is made from ABC. Secondly, the world $v_{1}$, at which the blocks of wood $\mathrm{A}_{1}-\mathrm{E}_{1}$ exist and a table, Woody $\mathrm{y}_{1}$ is made from $\mathrm{B}_{1} \mathrm{C}_{1} \mathrm{D}_{1}$, such that $<$ Woody $_{1}, \mathrm{~A}_{1}, \mathrm{~B}_{1}, \mathrm{C}_{1}, \mathrm{D}_{1}, \mathrm{E}_{1}>$ meets the qualitative condition Cond $<$ Woody, A, B, C, D, E>. Thirdly, the world $v_{2}$, at which the blocks $\mathrm{A}_{2}-\mathrm{E}_{2}$ exist and a table, Woody 2 , is made from $\mathrm{C}_{2} \mathrm{D}_{2} \mathrm{E}_{2}$, such that $<$ Woody $_{2}, \mathrm{~A}_{2}, \mathrm{~B}_{2}, \mathrm{C}_{2}, \mathrm{D}_{2}, \mathrm{E}_{2}>$ meets the qualitative condition Cond $<$ Woody $_{1}, \mathrm{~A}_{1}, \mathrm{~B}_{1}, \mathrm{C}_{1}, \mathrm{D}_{1}, \mathrm{E}_{1}>$. The following is true:

$$
\begin{aligned}
& \text { (30) (i) }<\text { Woody }_{1}, \mathrm{~A}_{1}, \mathrm{~B}_{1}, \mathrm{C}_{1}, \mathrm{D}_{1}, \mathrm{E}_{1}>\text { is a counterpart of }<\text { Woody, A, B, C, D, E }>\text {. } \\
& \text { (ii) }<\text { Woody }_{2}, \mathrm{~A}_{2}, \mathrm{~B}_{2}, \mathrm{C}_{2}, \mathrm{D}_{2}, \mathrm{E}_{2}>\text { is a counterpart of }<\mathrm{Woody}_{1}, \mathrm{~A}_{1}, \mathrm{~B}_{1}, \mathrm{C}_{1}, \mathrm{D}_{1} \text {, } \\
& \mathrm{E}_{1}>\text {. }
\end{aligned}
$$




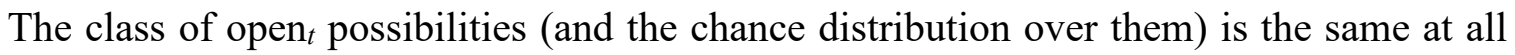
three open ${ }_{t}$ possibilities. By Necessity ${ }_{C P},<$ Woody $_{2}, \mathrm{~A}_{2}, \mathrm{~B}_{2}, \mathrm{C}_{2}, \mathrm{D}_{2}, \mathrm{E}_{2}>$ is not a counterpart of $<$ Woody, A, B, C, D, E $>$. Given that $\operatorname{ch}_{t, v_{1}}\left(\left\{v_{2}\right\}\right)=1 / 4$, we can infer the following by (26)(i) and (30)(ii):

(31) At $v_{1}, \operatorname{ch}_{t}\left(\right.$ Woody 1 is made from $\left.\mathrm{C}_{1} \mathrm{D}_{1} \mathrm{E}_{1}\right)=1 / 4$.

Moreover, given that actually $\operatorname{ch}_{t}\left(\left\{v_{1}\right\}\right)>0$, we can use (26)(ii) and (30)(i) to infer from (31) that the following actually holds:

(32) $\operatorname{ch}_{t}\left(\operatorname{ch}_{t}(\right.$ Woody is made from CDE $\left.)=1 / 4\right)>0$

However, by Necessity ${ }_{C P}$ and (24), $\neg \diamond$ Woody is made from CDE. Hence:

(33) $\operatorname{ch}_{t}($ Woody is made from CDE $)=0$.

(32) and (33) together are inconsistent with $\mathbf{4}_{t}^{\text {ch }}$ and they constitute a case of undermining, since they entail an instance of schema (29). (A counterexamples to $\mathbf{5}_{t}^{\text {ch }}$ could be constructed as well.)

The commitment to the possibility of undermining has many of the same problematic consequences for MPC-ists who endorse qualitative counterpart theory as for noncounterpart-theoretic MPC-ists. Given that $\operatorname{ch}_{u, v_{1}}\left(\left\{v_{2}\right\}\right)=1 / 2$, we can infer the following by (26)(i) and (30)(ii):

(34) At $v_{1}, \mathrm{ch}_{u}\left(\right.$ Woody $_{1}$ is made from $\left.\mathrm{C}_{1} \mathrm{D}_{1} \mathrm{E}_{1}\right)=1 / 2$.

Moreover, given that actually $\operatorname{ch}_{t}\left(\left\{v_{1}\right\}\right)>0$, we can use (26)(ii) and (30)(i) to infer from (34) that actually,

(35) $\operatorname{ch}_{t}\left(\operatorname{ch}_{u}(\right.$ Woody is made from CDE $\left.)=1 / 2\right)>0$.

(35) and (33) together are inconsistent both with $\mathbf{4}_{t, u}^{\mathrm{ch}}$, and therefore with the Expected Chance Principle. $\mathbf{4}_{t}^{O}, \mathbf{4}_{t, u}^{O}$, or $\mathbf{5}_{t}^{O}$ are violated as well. By counterpart-theoretic lights,

$\diamond_{t}^{o} \mathrm{R} a b \ldots n$ at $w$ iff some possible world $w^{*}$ that is like $w$ up to $t$ and conforms to $w^{\prime}$ 's laws contains individuals $a^{*}, b^{*}, \ldots, n^{*}$, such that $<a^{*}, b^{*}, \ldots, n^{*}>$ is a counterpart of $<a, b, \ldots, n>$ and $\mathrm{R} a^{*} b^{*} \ldots n^{*}$. 
$\diamond_{t}^{o} \diamond_{u}^{o} \mathrm{R} a b \ldots n$ at $w$ iff some possible world $w^{*}$ that is like $w$ up to $t$ and conforms to $w^{\prime}$ ' laws contains individuals $a^{*}, b^{*}, \ldots, n^{*}$, such that $\left\langle a^{*}, b^{*}, \ldots, n^{*}\right\rangle$ is a counterpart of $\left\langle a, b, \ldots, n>\right.$ and $\diamond_{u}^{o} \mathrm{R} a^{*} b^{*} \ldots n^{*}$ at $w^{*}$.

It is easy to see that in our example, $\diamond_{t}^{o} \diamond_{u}^{o} \mathrm{CDE}$ but $\neg \vartheta_{t}^{o} \mathrm{CDE}$. (The argument is essentially analogous to the one that shows that the example violates 4.) That is a counterexample to $\mathbf{4}_{t, u}^{o} \cdot \mathbf{4}_{t}^{o}$ and $\mathbf{5}_{t}^{o}$ are violated as well, as can be shown by analogous arguments.

Non-qualitative counterpart theorists can deny that there is a qualitative sufficient condition for an otherworldly object to be a counterpart of Woody or of $<$ Woody, A, B, C, D, E $>$. To the charge that their view generates undermining cases, they can then give a reply analogous to that of non-counterpart-theoretic MPC-ists who reject Sufficiency (see Sect. 3.5). They can say: "For any world $w$ that meets the following condition:

(36) $w$ contains an object $\mathrm{T}$ made from certain objects $b c d$, such that $\langle\mathrm{T}, b, c, d\rangle$ is a counterpart of $<$ Woody, B, C, D $>$,

there is another world $w^{*}$ that is qualitatively indistinguishable from $w$ but does not meet condition (36). (The objects that play the same qualitative roles in $w^{*}$ as T and $b-d$ in $w$ do not form an $n$-tuple that is a counterpart of $<$ Woody, B, C, D $>$.) Let $S$ be the class that

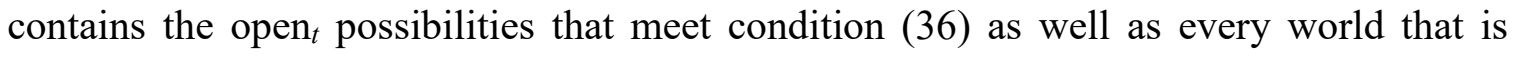
qualitatively like some open ${ }_{t}$ possibility that meets condition (36). I claim that, if the history up to $t$ and the laws are jointly compossible with some worlds that meet condition (36), then they are also compossible with some worlds in $S$ that fail to meet this condition. So, if the open ${ }_{t}$ possibilities include any worlds satisfying (36), they also include $S$-worlds not meeting that condition. Moreover, I hold that, if the class of open ${ }_{t}$ possibilities in $S$ has a non-zero chance at $t$ (say, 25\%), then there is only one way in which this chance can be divided up between those open ${ }_{t}$ possibilities in $S$ that meet condition (36) and those that do not: the latter receive the entire $25 \%$ while the former receive a chance of zero. Therefore, $\mathrm{ch}_{t}\left(\mathrm{BCD}_{\mathrm{W}}\right)=0$. Moreover, the open ${ }_{t}$ possibilities meeting condition (36) are the only ones containing entities T, $c, d, e$ such that $\langle\mathrm{T}, c, d, e>$ is a counterpart of $\langle$ Woody, C, D, E $>$ and $\diamond(T$ is made from $c d e)$. Therefore, actually $\operatorname{ch}_{t}\left(\diamond \mathrm{CDE}_{\mathrm{W}}\right)=0$ and consequently $\operatorname{ch}_{t}\left(\operatorname{ch}_{t}\left(\mathrm{CDE}_{\mathrm{W}}\right)>0\right)=0$. So, the chance at $t$ is zero that CDEw's chance at $t$ is different from what it actually is. That shows that on my account, Example 1 is not a case of undermining (and it does not violate $\mathrm{BCP} *, \mathbf{4}_{t}^{\text {ch }}$, or $\mathbf{5}_{t}^{\text {ch }}$ ). Similarly, it answers the objection that my account violates ECP (and $\mathbf{4}_{t, u}^{\mathrm{ch}}$ ).”

To make this response more compelling, the MPC-ist would need to provide some independent justification for the assumptions underlying it, in particular the claim that the 


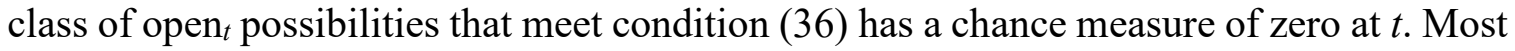
importantly, however, just like MPC-ists who deny Sufficiency, those who give the reply just considered cannot avoid violations of $\mathbf{4}_{t}^{O}, \mathbf{4}_{t, u}^{O}$, or $\mathbf{5}_{t}^{O}$. The argument given in $\S 3.5$ readily generalizes, as the reader can easily verify.

Counterpart-theoretic MPC-ists can adopt a dynamic view of de re modality by relativizing counterpart functions and the counterpart relation to a time (i.e., by making counterparthood a triadic relation between two objects and a time). They can then say that Necessity $_{C P}$ applies only to counterpart functions that are relativized to times at which it is already settled which parts the table will be made from. That will allow them to hold that, relative to time $t$ of the first coin toss, Woody 2 in world $v_{2}$ is a counterpart of Woody and $<$ Woody $_{2}, \mathrm{C}_{2}, \mathrm{D}_{2}, \mathrm{E}_{2}>$ is a counterpart of $<$ Woody, C, D, E $>$. But $<$ Woody $2, \mathrm{C}_{2}, \mathrm{D}_{2}, \mathrm{E}_{2}>$ is not a counterpart of $<$ Woody, C, D, E $>$ relative to times after the coin has landed and it has been settled that Woody will be made from $\mathrm{ABC}$. Consequently, $\diamond_{t} \mathrm{CDE}$ Wut $\neg \nabla_{u} \mathrm{CDE}$. Counterpart-theoretic MPC-ists who endorse this dynamic view can avoid the problems discussed in this paper in the manner described in $\$ 3.5$. But unless they can provide independent motivation for making de re modal facts time-relative, it will seem like an ad hoc maneuver. ${ }^{22}$

\section{Alternatives to MPC}

While by no means providing knock-down arguments against MPC, $\S \S 3$ and 4 highlighted problems for the view that give us reasons to look for an alternative. What are the options?

One possibility is to reject (3) along with Necessity. Another is to deny (4) and Tolerance. Both of these options are costly, as (3) and (4) are very plausible. A third option, which avoids these costs, is to endorse (37).

(37) (3) and (4) are true. Moreover, contrary to MPC, they are necessary, for everything necessarily has the modal profile it does.

I will first consider what this response would look like for proponents of non-counterparttheoretic MPC before turning to the counterpart-theoretic version. It is actually true that Woody could have been made from $\mathrm{ABX}$ but not from $\mathrm{CDE}$, and non-counterpart-theoretic MPC-ists who endorse (37) have to say that these modal claims are true even at possible worlds where Woody is made from BCD. Thus, Woody conforms to Necessity and Tolerance in actuality but not at possible worlds where $\mathrm{BCD}_{\mathrm{W}}$ holds. Necessity and

\footnotetext{
${ }^{22}$ I argued in Kment (2012) that qualitative counterpart theory yields implausible consequences about chance. These difficulties are independent of, and additional to, those for counterpart-theoretic MPC-ists outlined in this section.
} 
Tolerance do not hold for all tables in all possible worlds or even for the tables in all nearby worlds.

The obvious objection to this view is that it makes the metaphysical order of the universe seem implausibly fragile. The realm of de re modal facts is actually governed by certain general principles about which kinds of objects have which of their features necessarily. The principles include the universal claims that are in the scope of the necessity operators in Necessity and Tolerance (the claims you obtain by removing the necessity operators at the beginning) - call them 'Necessity', and 'Tolerance', . But on the view described in the preceding paragraph, Necessity ${ }^{-}$and Tolerance ${ }^{-}$would have been false if some actual tables had been made from slightly different parts. Does that not mean that the modal facts would then have been less orderly than they actually are (tables made from the same parts as in actuality would have conformed to Necessity ${ }^{-}$and Tolerance ${ }^{-}$while others would not have)? It seems that some scratches in a few blocks of wood would have been enough to upset the metaphysical order. Worse, once we accept that actuality is surrounded in modal space by metaphysically disordered worlds, we have to wonder how we can be so sure that the actual world is an orderly one. All of this sounds rather strange.

To answer this objection, proponents of (37) need to give an account of the principles governing de re modality that does not include Necessity ${ }^{-}$or Tolerance ${ }^{-}$but only principles that are more counterfactually robust. One option is to adopt what we may call 'maximal multi-thingism,' the view that at all metaphysically possible worlds, the facts of de re modality are governed by the following principle (see Leslie 2011, Kment 2014, pp. 1947): $:^{23}$

(38) For any material object $x$ and any set $\mathrm{S}$ of $x$ 's properties that meets certain minimal conditions, there is an object $x^{*}$ that is co-located with $x$ and made from the same parts as $x$, such that the properties that $x^{*}$ has necessarily include all and only those in $\mathrm{S}$.

On this account, there is no difference between the principles governing de re modality in actuality and at $\mathrm{BCD}_{\mathrm{W}}$-worlds. Just as Necessity ${ }^{-}$and Tolerance fail for Woody at $\mathrm{BCD}_{\mathrm{W}}-$ worlds, they fail for many tables co-located with Woody at the actual world. For example, Tolerance ${ }^{-}$fails for those tables co-located with Woody that could not have been made from parts other than $\mathrm{ABC}$. And just as Woody conforms to Necessity ${ }^{-}$and Tolerance ${ }^{-}$in actuality, many tables that are co-located with Woody at a $\mathrm{BCD}_{\mathrm{W}}$-world conform to these two principles. Moreover, both in actuality and at $\mathrm{BCD}$-worlds, the facts of de re modality are governed by the same general principle: (38). There is nothing fragile about the metaphysical order.

${ }^{23}$ I borrowed the term 'multi-thingism' from Karen Bennett (2004), who writes that she picked it up from Stephen Yablo. 
Counterpart theorists who wish to endorse (37) can easily do so. They will endorse the usual counterpart-theoretic strategy of explaining the fact that $\diamond \mathrm{BCD}_{\mathrm{W}}$ by saying that the counterparts of $<$ Woody, B, C, D $>$ include some quadruple whose first member is made from its other members (such as the quadruple $<$ Woody $_{1}, \mathrm{~B}_{1}, \mathrm{C}_{1}, \mathrm{D}_{1}>$ of entities in world $v_{1}$ depicted in Figure 3). Similarly, they will explain the fact that $\neg \checkmark \mathrm{CDE}_{\mathrm{W}}$ by denying that the counterparts of $<$ Woody, C, D, E $>$ include any quadruple whose first member is made from the others. But they will reject MPC, by saying that (3) and (4), and all other truths about the modal profiles of individuals, are necessary truths. One possible way they can do this is to say that counterparthood is an equivalence relation. On this view, a counterpart of $x$ has the same counterparts as $x$ itself (so that there are no cases where it could have been possible for $x$ to meet a certain condition but it is not actually possible). Hence, no counterpart of $<$ Woody, C, D, E $>$, not even the quadruple $<$ Woody $_{1}, \mathrm{C}_{1}, \mathrm{D}_{1}, \mathrm{E}_{1}>$ of entities in $v_{1}$, has a counterpart whose first member is made from the others. So, Tolerance $\mathrm{CP}_{\mathrm{C}}$, while true of Woody, cannot be true of Woody. Does that mean that the metaphysical order governing de re modality is very fragile, in the sense that the criteria for counterparthood that apply to individuals at nearby worlds differ significantly from those applying to actual individuals?

Non-qualitative counterpart theorists can avoid this conclusion by endorsing a counterpart-theoretic version of maximal multi-thingism. On that view, every physical object is co-located with many others that have the same qualitative non-modal properties but differ in the range of their counterparts. Hence, just as Woody at the actual world conforms to Tolerance ${ }_{C P}$, so do many tables that are co-located with Woody ${ }_{1}$ at $v_{1}$. And just as Woody fails to conform to Tolerance $_{C P}$, so do many tables co-located with Woody at the actual world. At both worlds, the same multi-thingist principles govern the range of a thing's counterparts. Qualitative counterpart theorists are in a less good position to accept this account. On their view, the range of an object's counterparts (and hence its modal properties) is determined by its non-modal qualitative properties. For there to be co-located objects that differ in their counterparts, there would have to be relevant differences between the non-modal qualitative properties of these objects, and it is not clear what these differences could be.

This is not the place to review the complex debate about the virtues and vices of (maximal) multi-thingism (Varzi 2012, Wasserman 2013), or to discuss how plausible it ultimately is to combine the view with non-qualitative counterpart theory. What is important for present purposes is to observe that multi-thingism provides one alternative to MPC that merits further exploration. 


\section{Modal-existence contingentism}

Some philosophers hold that, necessarily, every possible world existentially depends on the individuals inhabiting it, that is, it could not have existed without all of them existing. ${ }^{24}$ Since most of these philosophers also believe that that some individuals exist contingently, ${ }^{25}$ they conclude that possible worlds where such individuals exist are contingent existents as well (see Fine 1977, Adams 1981, Stalnaker 2011, Kment 2014, $\S 4.5$; cp. McMichael 1983). For example, a possible world $w$ where Woody exists fails to exist at possible worlds where Woody does not exist. Moreover, some who draw this conclusion believe that (39) is necessarily equivalent to (40).

(39) Possibly, Woody exists.

(40) There exists a possible world where Woody exists.

Since they think that (40) is false at possible worlds where Woody does not exist, they conclude that the same is true of (39). So, while (39) is actually true, it could have been false. Call the form of modal contingentism that is motivated in this way modal existence contingentism (MEC) (Adams 1981, Kment 2014, Ch. 4, in particular $\$ 4.7 b$ ). ${ }^{26}$

MEC generates undermining cases. Suppose at $t$ you decide to toss a fair coin. There are two open ${ }_{t}$ possibilities: $w_{1}$, where the coin lands heads and you make a table (called 'Woody') from $\mathrm{ABC}$, and $w_{2}$, where it lands tails and you burn $\mathrm{ABC}$. $\operatorname{ch}_{t}\left(\left\{w_{1}\right\}\right)=\operatorname{ch}_{t}\left(\left\{w_{2}\right\}\right)=1 / 2$. Woody does not exist at $w_{2}$. By MEC-ist lights, it follows that at $w_{2}, \neg \diamond$ Woody exists. By the Modality-Chance Principle (MC), ' $\mathrm{ch}_{t}$ (Woody exists) $>0$ ' necessitates ' $\diamond$ Woody exists'. Hence,

(41) At $w_{2}, \neg\left(\operatorname{ch}_{t}(\right.$ Woody exists $\left.)>0\right)$.

Given MC, (41) and the fact that $\operatorname{ch}_{t}\left(\left\{w_{2}\right\}\right)=1 / 2$ entail that $\operatorname{ch}_{t}\left(\operatorname{ch}_{t}(\right.$ Woody exists $\left.)>0\right) \neq 1$. And yet, $\operatorname{ch}_{t}($ Woody exists $)=\operatorname{ch}_{t}\left(\left\{w_{1}\right\}\right)>0$. That violates $\mathbf{5}_{t}^{\text {ch }}\left(\nabla_{t}^{\text {ch }} \mathrm{P} \rightarrow \square_{t}^{\text {ch }} \nabla_{t}^{\text {ch }} \mathrm{P}\right)$ and therefore UII. This example of undermining follows the pattern described in the introduction. The chance at $t$ of Woody's existence depends on whether $\diamond$ Woody exists: it is positive at the open ${ }_{t}$ possibility $\left(w_{1}\right)$ where $\diamond$ Woody exists but equals zero at the open ${ }_{t}$ possibility $\left(w_{2}\right)$ where $\neg \diamond$ Woody exists. Moreover, it is chancy at $t$ whether $\diamond$ Woody exists, since it depends on whether Woody will in fact exist. So, the chances at $t$ depend on modal facts that are themselves chancy at $t$. That is a recipe for undermining cases.

\footnotetext{
${ }^{24}$ See Plantinga 1983 for the opposite view.

${ }^{25}$ See Linsky and Zalta 1994, 1996, Williamson 1998, 2013 for arguments against contingent existence.

${ }^{26}$ Not everyone who believes that some possible worlds exist contingently accepts the necessary equivalence of (39) and (40) and endorses modal contingentism in my sense. See Stalnaker 2011.
} 
It remains a topic for future work to study the extent to which MEC generates the various other problems associated with undermining cases that were discussed in $\S \S 3-4$, and what replies to the problem(s) are available to MEC-ists.

\section{Summary and conclusion}

A theory about modal space should be consistent with a plausible account of physical chance. This constraint creates difficulties for philosophers who reject $\mathbf{4}$ or $\mathbf{5}$ and who hold that the chances at a given time can depend on modal facts that are partly determined by later chance processes. These philosophers, who include proponents of MPC and MEC, also have to deny various compelling S4- and S5-principles about chance and open possibility.

I mentioned in $\$ 2$ that I have very few untutored opinions about the formal properties of the metaphysical modalities and therefore find it hard to know offhand what to think of 4 or 5. By contrast, the S4- and S5-principles about chance and open possibility discussed in this paper are immediately compelling, and some of them follow from very plausible principles of greater generality such as UII and ECP. This is not particularly surprising: unlike the notion of metaphysical possibility, the concepts of chance and open possibility arguably figure frequently in non-philosophical thinking. Moreover, it points to one important reason why it can be helpful in deciding controversies about modality to consider the implications of the competing views for the theory of chance: it allows us to draw on views we have about chance and the range of open possibilities that are often much firmer than those about metaphysical modality. ${ }^{27}$

\section{References}

Adams, Robert 1981, 'Actualism and Thisness', in Synthese 49

Bandyopadhyay, Prasanta S., and Malcolm R. Forster (eds.) 2011, Handbook of the Philosophy of Science, vol. 7: Philosophy of Statistics (Oxford: Elsevier)

Bennett, Karen 2004, 'Spatio-temporal Coincidence and the Grounding Problem', in Philosophical Studies 118

Bigelow, John, John Collins, and Robert Pargetter 1993, 'The Big Bad Bug: What are the Humean's Chances?', in British Journal for the Philosophy of Science 44

Chandler, Hugh 1976, 'Plantinga and the Contingently Possible', in Analysis 36

\footnotetext{
${ }^{27}$ For helpful comments, I am indebted to Cian Dorr, Adam Elga, Alan Hájek, Karen Lewis, David Manley, Alex Meehan, Carla Merino-Rajme, Kristin Primus, Jonathan Schaffer, Jack Spencer, the participants of a graduate seminar at Princeton, the audiences at talks I gave at Oxford University, the Chambers Modality Conference at the University of Nebraska, and the conference on haecceitism at the University of Neuchâtel, and to the anonymous referees of this paper.
} 
De Finetti, Bruno 1972, Probability, Induction and Statistics (London: Wiley)

Fara, Delia 2009, 'Dear Haecceitism', in Erkenntnis 70

Fara, Michael, and Timothy Williamson 2005, 'Counterparts and Actuality', Mind 114

Fine, Kit 1977, 'Postscript: Prior on the Construction of Possible Worlds and Instants', in

A. N. Prior and K. Fine, Worlds, Times, and Selves (Amherst: University of Massachusetts Press)

Forbes, Graeme 1985, The Metaphysics of Modality (Oxford: Oxford University Press)

Hájek, Alan 2011, 'Conditional Probability', in P. S. Bandyopadhyay and M. R. Forster (eds.), Handbook of the Philosophy of Science, vol. 7: Philosophy of Statistics (Oxford: Elsevier)

Hall, Ned 1994, 'Correcting the Guide to Objective Chance', in Mind 103

Hazen, Allen 1979, 'Counterpart-Theoretic Semantics for Modal Logic', in Journal of Philosophy 76

Howson, Colin 2008, 'De Finetti, Countable Additivity, Consistency and Coherence', in British Journal for the Philosophy of Science 59

Kment, Boris 2012, 'Haecceitism, Chance, and Counterfactuals', in Philosophical Review 121.

Kment, Boris 2014, Modality and Explanatory Reasoning (Oxford: Oxford University Press).

Leslie, Sarah-Jane 2011, 'Essence, Plenitude, and Paradox', in Philosophical Perspectives 25

Lewis, David 1968, 'Counterpart Theory and Quantified Modal Logic', in Journal of Philosophy 65

_ 1986a, 'A Subjectivist's Guide to Objective Chance', in his Philosophical Papers, vol. 2 (Oxford: Oxford University Press)

-1986a, On the Plurality of Worlds (Oxford: Blackwell) 1994, 'Humean Supervenience Debugged', in Mind 103

Linsky, Bernard, and Edward Zalta 1994, 'In Defense of the Simplest Quantified Modal Logic', in J. Tomberlin, Philosophical Perspectives 8: Logic and Language (Atascadero: Ridgeview Press)

_ 1996, 'In Defense of the Contingently Concrete', in Philosophical Studies 84

McMichael, Alan 1983, 'A Problem for Actualism about Possible Worlds', in Philosophical Review 92

Nolan, Daniel 2016, 'Chance and Necessity', in Philosophical Perspectives 30.

Plantinga, Alvin 1983, 'On existentialism', Philosophical Studies 44

Rényi, Alfréd 1970, Foundations of Probability (San Francisco: Holden-Day)

Russell, Jeffrey 2013, 'Actuality for Counterpart Theorists', in Mind 122

Skow, Brad 2008, 'Haecceitism, Anti-Haecceitism and Possible Worlds', in Philosophical Quarterly 58 
Stalnaker, Robert 2011, Mere Possibilities: Metaphysical Foundations of Modal Semantics (Princeton, NJ: Princeton University Press)

Thau, Michael 1994, 'Undermining and Admissibility', in Mind 103

Varzi, Achille 2012, 'Mereology', in Stanford Encyclopedia of Philosophy $<$ http://plato.stanford.edu/archives/win2012/entries/mereology/>

Wasserman, Ryan 2013, 'Material Constitution', in Stanford Encyclopedia of Philosophy $<$ http://plato.stanford. edu/archives/sum2013/entries/material-constitution/>

Williamson, Timothy 1998, 'Bare Possibilia', in Erkenntnis 48

2013, Modal Logic as Metaphysics, (Oxford: Oxford University Press) 